\title{
Electronic Structure of the Peroxy Intermediate and Its Correlation to the Native Intermediate in the Multicopper Oxidases: Insights into the Reductive Cleavage of the O-O Bond
}

\author{
Jungjoo Yoon and Edward I. Solomon * \\ Department of Chemistry, Stanford University, Stanford, California 94305
}

\begin{abstract}
The multicopper oxidases (MCOs) utilize a blue type 1 (T1) copper site and a trinuclear $\mathrm{Cu}$ cluster comprised of a type 2 (T2) and a binuclear type 3 (T3) site that together catalyze the four-electron reduction of $\mathrm{O}_{2}$ to $\mathrm{H}_{2} \mathrm{O}$. Reaction of the fully reduced enzyme with $\mathrm{O}_{2}$ proceeds via two sequential two-electron steps generating the peroxy intermediate (PI) and the native intermediate (NI). While a detailed description of the geometric and electronic structure of NI has been developed, this has been more elusive for PI largely due to the diamagnetic nature of its ground state. Density functional theory (DFT) calculations have been used to correlate to spectroscopic data to generate a description of the geometric and electronic structure of PI. A highly conserved carboxylate residue near the T2 site is found to play a critical role in stabilizing the PI structure, which induces oxidation of the T2 and one $\mathrm{T} 3 \mathrm{Cu}$ center and strong superexchange stabilization via the peroxide bridge, allowing irreversible binding of $\mathrm{O}_{2}$ at the trinuclear $\mathrm{Cu}$ site. Correlation of PI to NI is achieved using a twodimensional potential energy surface generated to describe the catalytic two-electron reduction of the peroxide $\mathrm{O}-\mathrm{O}$ bond by the MCOs. It is found that the reaction is thermodynamically driven by the relative stability of NI and the involvement of the simultaneous two-electron transfer process. A low activation barrier (calculated $\sim 5-6 \mathrm{kcal} / \mathrm{mol}$ and experimental $\sim 3-5 \mathrm{kcal} / \mathrm{mol}$ ) is produced by the triangular topology of the trinuclear $\mathrm{Cu}$ cluster site, as this symmetry provides good donoracceptor frontier molecular orbital (FMO) overlap. Finally, the O-O bond cleavage in the trinuclear $\mathrm{Cu}$ cluster can be achieved via either a proton-assisted or a proton-unassisted process, allowing the MCOs to function over a wide range of $\mathrm{pH}$. It is found that while the proton helps to stabilize the acceptor $\mathrm{O}_{2}{ }^{2-} \sigma^{*}$ orbital in the proton-assisted process for better donor-acceptor FMO overlap, the third oxidized $\mathrm{Cu}$ center in the trinuclear site assumes the role as a Lewis acid in the proton-unassisted process for similarly efficient $\mathrm{O}-\mathrm{O}$ bond cleavage.
\end{abstract}

\section{Introduction}

Multicopper oxidases (MCOs) are a family of enzymes that catalyze the four-electron reduction of $\mathrm{O}_{2}$ to $\mathrm{H}_{2} \mathrm{O}$ with concomitant oxidations of substrates.1,2 To carry out their functions, all MCOs utilize the redox properties of four $\mathrm{Cu}$ centers: The electrons are taken up at the type 1 (T1) blue $\mathrm{Cu}$ site and transferred $\sim 13$ Á to the trinuclear $\mathrm{Cu}$ cluster site comprised of a type 2 (T2) normal $\mathrm{Cu}$ site and a type 3 (T3) coupled-binuclear copper site, ${ }^{3,4}$ where the four-electron reduction of $\mathrm{O}_{2}$ to $\mathrm{H}_{2} \mathrm{O}$ occurs. In the fully-oxidized resting form of the enzyme, each of the two $\mathrm{T} 3 \mathrm{Cu}$ centers is held in the protein by three His ligands and are bridged by a $\mathrm{OH}^{-}$ligand, while the $\mathrm{T} 2$ is held by two His ligands and has an $\mathrm{OH}^{-}$ligand outside the cluster (Figure 1). $5-15$ 
The catalytic cycle is initiated by the reaction of the fully reduced enzyme with $\mathrm{O}_{2}$. In the fully reduced form, the $\mathrm{T} 3 \mathrm{OH}^{-}$bridging ligand and $\mathrm{T} 2 \mathrm{OH}^{-}$ligand are lost, leading to a coordinatively unsaturated trinuclear $\mathrm{Cu}$ cluster. ${ }^{14,16,17}$ The reaction of the fully reduced enzyme with $\mathrm{O}_{2}$ proceeds via two sequential two-electron steps, generating the peroxy intermediate (PI) and the native intermediate (NI). In the holo-enzyme, only the four-electron reduced NI has been trapped ${ }^{18-22}$ as the second two-electron process is very fast $(k>350$ $\left.\mathrm{s}^{-1}\right), 23$ effectively resulting in one four-electron process. Extensive spectroscopic studies on $\mathrm{NI},{ }^{18}$ combined with model ${ }^{24-28}$ and computational studies, ${ }^{29}$ have demonstrated that NI is a fully oxidized species with $\mathrm{O}_{2}$ fully reduced to water-level products that remain bound to the trinuclear site as $\mu_{3}$-oxo and $\mu_{2}$-hydroxo bridging ligands.

Alternatively, PI has been trapped and characterized using T1-depleted derivatives of MCOs, where the $\mathrm{T} 1$ is either replaced by a spectroscopic and redox-innocent $\mathrm{Hg}^{2+}$ ion in the case of laccase $(\mathrm{T} 1 \mathrm{HgLc}), 23,30,31$ or simply knocked out by mutating the Cys residue at the $\mathrm{T} 1$ site to Ser in Fet3p (T1D). ${ }^{32-35}$ In the T1D forms, only three electrons are nominally available to reduce $\mathrm{O}_{2}$, of which two from the three $\mathrm{Cu}$ centers in the trinuclear site are transferred to $\mathrm{O}_{2}$. This leads to the formation of PI in a pH-independent and rapid process $\left(k \sim 2 \times 10^{6}\right.$ $\left.\mathrm{M}^{-1} \mathrm{~s}^{-1}\right) .{ }^{23,36}$ Alternatively, the decay of PI is very slow and $\mathrm{pH}$ dependent $\left(k \sim 0.003 \mathrm{~s}^{-1}\right.$ at $\mathrm{pH}=4.7$ and $k \sim 0.0003 \mathrm{~s}^{-1}$ at $\mathrm{pH} 7.5$ for T1HgLc, $\left.\mathrm{pK}_{\mathrm{a}} \sim 5.7\right) .{ }^{23,34,35}$ It exhibits different kinetic behavior at different $\mathrm{pH}$ conditions, where an inverse proton kinetic isotope effect is observed at low $\mathrm{pH}\left(k_{H} / k_{D}=0.89\right)$, while no such effect is observed at high $\mathrm{pH}\left(k_{H} / k_{D} \sim 1\right)$. $23,34,35,37$ Importantly, it has been found by MCD spectroscopy that PI decays via an "NIlike" species. ${ }^{31}$ This, along with the similar rate of formation of PI and NI, has indicated PI is a kinetically competent precursor to NI. ${ }^{23,31}$

The geometric and electronic structure of PI is less well defined than that of NI due the diamagnetic nature of its ground state $\left(\mathrm{S}_{\mathrm{tot}}=0,-2 J>200 \mathrm{~cm}^{-1}\right) .{ }^{31}$ Earlier studies have suggested that two electrons are donated by the two T3 Cu's in the trinuclear site to $\mathrm{O}_{2}$ upon formation of $\mathrm{PI}$ in analogy to the $\mathrm{O}_{2}$ reactivities in the other T3 sites in biology, hemocyanin (Hc) and tyrosinase (Tyr), where the oxy-forms acquire a $\mu-\eta^{2}: \eta^{2}$ side-on bridged geometric and electronic structure. ${ }^{38-40}$ However, the spectral features of PI are very different from those of oxy-Hc and oxy-Tyr, indicating that the PI acquires a very different geometry. ${ }^{31}$ It has been suggested that the peroxide must be bound internally in the trinuclear site as a T2-T3 bridging ligand, ${ }^{23,31}$ which is supported by a spectroscopic study of the peroxy adduct (PA) of T1HgLc, ${ }^{41}$ a crystallographic study of the PA of CotA, ${ }^{17}$ and QM/MM calculations of PI and PA. ${ }^{29}$

In this study, extensive DFT calculations are correlated to spectroscopic data to develop the geometric and electronic structure of PI. This is then correlated to that of NI, which has been rigorously defined in previous studies, ${ }^{24-28}$ to elucidate the reductive cleavage of the O-O bond (i.e. PI $\rightarrow \mathrm{NI})$. The roles of two highly conserved carboxylate residues $\left(\mathrm{D}_{94}\right.$ and $\mathrm{E}_{487}$ in Fet3p, Figure 1) in the outer coordination sphere of the trinuclear cluster site are also evaluated and found to be essential in the stabilization of the PI structure and in proton donation in the $\mathrm{O}-\mathrm{O}$ bond cleavage step. This study provides new molecular level insights into the role of the trinuclear $\mathrm{Cu}$ cluster site in the reaction mechanism of catalytic $\mathrm{O}_{2}$ reduction in the MCOs.

\section{Computational Details}

DFT calculations were performed using Gaussian 03,42 implementing the broken-symmetry method. ${ }^{43}$ All geometry optimizations were performed using B3LYP functional ${ }^{44}$ with double- basis sets $6-31 \mathrm{G}^{*}$ for $\mathrm{Cu}$ and coordinated N/O atoms and 3-21G* for the rest. The starting geometry of the trinuclear $\mathrm{Cu}$ site was adapted from the crystal structure of Trametes versicolor laccase (1GYC, Res. $1.9 \AA),{ }^{9}$ where the His ligands were replaced by imidazolyl 
ligands. To reflect the features of the crystal structure, (a) the positions of the $\mathrm{H}$ atoms that replaced the side chains to the protein backbone and those bound to His $\mathrm{N}$ not bound to $\mathrm{Cu}$ (which are all involved in hydrogen bonds) were fixed, (b) the angle of the $\mathrm{O}$ atom on the $\mathrm{T} 2$ water-derived ligand relative to the plane of the two T2 His rings to prevent it from artificial binding to the nearby $\mathrm{T} 3$ His ligands was fixed, and (c) the three $\mathrm{N}-\mathrm{T} 3_{\mathrm{A}}-\mathrm{T} 3_{\mathrm{B}}-\mathrm{N}$ dihedral angles $\left(\mathrm{T} 3_{\mathrm{A}}\right.$ and $\mathrm{T} 3_{\mathrm{B}}$ are defined in Figure 1), where the N's are the coordinated atoms of the eclipsed His ligands, were fixed to keep the eclipsed conformation as found in the crystal structures of all MCOs. Note that the flexibility of the model was not affected by these constraints, as exemplified by the wide range of $\mathrm{T} 3_{\mathrm{A}}-\mathrm{T} 3_{\mathrm{B}}$ distances found in different structures (e.g. in PI, $\mathrm{R}\left(\mathrm{T} 3_{\mathrm{A}}-\mathrm{T} 3_{\mathrm{B}}\right)=4.07 \AA$ and in NI, $\left.\mathrm{R}\left(\mathrm{T} 3_{\mathrm{A}}-\mathrm{T} 3_{\mathrm{B}}\right)=3.01 \AA\right)$. Additional details of the individual models are given in Results and Analysis. The resulting optimized structures of PI (with $\mathrm{D}_{94}$ ), $\mathrm{PI}+\mathrm{e}, \mathrm{PI}+\mathrm{e}+\mathrm{H}, \mathrm{TS}_{1}, \mathrm{TS}_{2}$, and $\mathrm{NI}$ (vide infra; the coordinates of these structures are given in Supplementary Information) were further used for single-point calculations with the B3LYP functional using the triple- basis set 6-311G* for $\mathrm{Cu}$ and coordinated N/O atoms and double6-31G* for the rest. Solvation effects were also considered for PI+e, PI+eH, $\mathrm{TS}_{1}, \mathrm{TS}_{2}$, and NI (vide infra) using the polarized continuum model as implemented in Gaussian 03 (PCM/ UAKS) with a dielectric constant of 4.0 to reflect the protein dielectric media. The molecular orbital (MO) compositions were obtained using PyMOlize. 45

\section{Results and Analysis}

\section{A. The Peroxy Intermediate}

i. Geometric Structure of PI-To obtain a spectroscopically relevant structure of PI, we have performed spin unrestricted DFT calculations, where $\mathrm{O}_{2}$ is bound internally to the cluster as implicated by previous spectroscopic ${ }^{41}$ and QM/MM computational results. ${ }^{29,46} \mathrm{H}_{2} \mathrm{O}$ was chosen as the water-derived ligand on the $\mathrm{T} 2$ center and the internal peroxide was kept unprotonated, following earlier kinetic data 23 indicating that the formation of $\mathrm{PI}$ is a $\mathrm{pH}$ independent process.

Initially, model systems with only the ligands that are directly coordinated to the three $\mathrm{Cu}$ centers (the eight His and the $\mathrm{T} 2 \mathrm{H}_{2} \mathrm{O}$, Figure 1) were considered. All geometry optimizations were performed in the broken symmetry $\mathrm{M}_{\mathrm{S}}=0\left(\left\langle\mathrm{~S}^{2}\right\rangle \approx 1.0\right)$ states. Two structures were obtained, one with a side-on $\mu-\eta^{2}: \eta^{2}-\mathrm{O}_{2}{ }^{2-}$ geometry and the other with a $\mu_{3}-1,1,2-\mathrm{O}_{2}{ }^{2-}$ geometry (Figure 2 and Table 1; additional geometric parameters and spin densities are listed in Tables S1 and S2). ${ }^{47}$ The former is reminiscent of oxy-Hc/Tyr, $1,2,48$ while the latter is similar to that obtained in the QM/MM calculations of PI. 29,46 Both structures have singlet ground states, the side-on structure with $J \sim-3700 \mathrm{~cm}^{-1}$ and the $\mu_{3}-1,1,2$ structure with $J \sim$ $-54 \mathrm{~cm}^{-1,49}$ reasonably consistent with experiment $\left(-2 J>200 \mathrm{~cm}^{-1}\right) .31$

Of these two structures, the side-on structure was found to be energetically more stable by $\sim 7.7$ $\mathrm{kcal} / \mathrm{mol}$ (pure singlet $\mathrm{S}_{\text {tot }}=0$ energy comparisons from projection of the broken symmetry $\mathrm{M}_{\mathrm{S}}=0$ energies). ${ }^{49}$ However, this is inconsistent with experiment, as PI does not exhibit the spectral features of the side-on bridged structure as found in oxy-Hc/Tyr and its model complexes, which are characterized by a prominent band in the absorption spectrum at $\sim 340$ $\mathrm{nm}$ with $\varepsilon \sim 20000-25000 \mathrm{M}^{-1} \mathrm{~cm}^{-1}$ (see Figure S1). ${ }^{1,2,48,50} \mathrm{In}$ PI, while an absorption band at a similar energy is also observed, its intensity is $4-5$ fold lower (vide infra), indicating that the side-on bridged structure is not present in PI. ${ }^{31}$

Modified structures were then considered, implementing the possible effect of a nearby carboxylate residue, $\mathrm{D}_{94}$ (following the residue numbering in Fet3p, Figure 1), which is highly conserved throughout all known MCOs. ${ }^{5-15}$ X-ray crystal structures indicate that the carboxylate moiety of this residue is involved in hydrogen bonding interactions with both the $\mathrm{T} 2$ water-derived ligand (mediated by a water molecule) and a $\mathrm{T} 3_{\mathrm{B}}$ His ligand (Figure 1). In 
addition, the backbone carbonyl group of this residue is also hydrogen bonded to the $\delta \mathrm{N}$ of one of the T2 His ligands (Figure 1). In fact, the hydrogen bonding connectivity of this residue has been observed to affect the $\mathrm{T} 2 \mathrm{Cu}^{\mathrm{II}}$ site in the resting enzyme, ${ }^{51}$ suggestive of a critical role in keeping the structural stability and in tuning the reactivity of the trinuclear cluster site. In addition, mutation of this residue to an uncharged residue, Ala or Asn, in Fet3p resulted in complete loss of $\mathrm{O}_{2}$ reactivity. ${ }^{35}$ Alternatively, the $\mathrm{O}_{2}$ reactivity is completely retained in the $\mathrm{D}_{94} \mathrm{E}$ mutant of Fet $3 \mathrm{p}$, suggesting that the negative charge of $\mathrm{D}_{94}$ plays a significant role in the formation of PI. 35,37

$\mathrm{D}_{94}$ was implemented in both the $\mu-\eta^{2}: \eta^{2}-\mathrm{O}_{2}{ }^{2-}$ side-on and $\mu_{3}-1,1,2-\mathrm{O}_{2}{ }^{2-}$ structures using a formate ion and a water molecule that mediates hydrogen bonding interactions between $\mathrm{D}_{94}$ and the T2 water-derived ligand in the enzyme (Figure 2(b)). The $\mathrm{H}$ atom of the formate ion was fixed in position during the optimization, while other atoms of the formate ion and the water molecule were freely optimized. As a result, the $\mu_{3}-1,1,2-\mathrm{O}_{2}{ }^{2-}$ structure became more stable than the side-on structure by $\sim 6.5 \mathrm{kcal} / \mathrm{mol}$ (pure singlet $\mathrm{S}_{\text {tot }}=0$ energy comparisons from projection of the broken symmetry $\mathrm{M}_{\mathrm{S}}=0$ energies). ${ }^{49}$ The marked stabilization of the $\mu_{3}-1,1,2-\mathrm{O}_{2}{ }^{2-}$ structure derives from stronger $\mathrm{T} 2$ - and $\mathrm{T} 3_{\mathrm{B}}$-peroxide bonding interactions induced by the negative charge of $\mathrm{D}_{94}$ that lowers the reduction potentials of these $\mathrm{Cu}$ centers. In addition, the calculated $J$ is $-670 \mathrm{~cm}^{-1}$ and it represents a highly stabilized singlet ground state via strong antiferromagnetic superexchange interactions. The $\mu_{3}-1,1,2$ bridged geometry is also consistent with the EXAFS data, in which an intense outer-shell peak at $\sim 3.4 \AA$ is observed. ${ }^{31}$ This EXAFS feature likely derives from the $\mathrm{T} 2-\mathrm{T} 3_{\mathrm{B}} \mathrm{Cu}$ pair (calculated distance $=3.68 \AA$, Table 1 ), as the strong $\mathrm{T} 2$ - and $\mathrm{T} 3_{\mathrm{B}}$-peroxide bonding interactions and the tight $\mathrm{T} 2$ $\mathrm{O}_{2}{ }^{2-}-\mathrm{T} 3_{\mathrm{B}}$ bridge would promote the favorable Debye-Waller factor required for the intense outer-shell peak $\left(\mathrm{T} 3_{\mathrm{A}}\right.$ and $\mathrm{T} 3_{\mathrm{B}}$ are defined in Figure 2).

ii. Electronic Structure of PI: Correlation to Spectroscopy-Due to the lack of EPR and MCD features, specific assignments of the oxidation states of the three $\mathrm{Cu}$ centers in PI have been difficult. While it has been previously proposed that the two T3 $\mathrm{Cu}$ 's in PI are oxidized as in Hc/Tyr, the distinct nature of the T3 sites in MCOs relative to Hc/Tyr has been demonstrated with the T2-depleted derivative of $\mathrm{Lc}$ which lacks any affinity towards $\mathrm{O}_{2} .{ }^{52-}$ 54

In the calculated $\mu_{3}-1,1,2$ bridged PI structure with $\mathrm{D}_{94}$ (Figure 2(b)), it is found that the $\mathrm{T} 2$ and $\mathrm{T} 3_{\mathrm{B}}$ are oxidized and $\mathrm{T} 3_{\mathrm{A}}$ reduced. This description of the oxidiation states of the $\mathrm{Cu}$ centers in PI is consistent with the available spectroscopic data on PI and its structural analog, the peroxy adduct (PA). ${ }^{41}$ In PA, which is obtained by binding $\mathrm{H}_{2} \mathrm{O}_{2}$ to the fully oxidized trinuclear $\mathrm{Cu}$ cluster in $\mathrm{T} 1 \mathrm{HgLc}$, all three $\mathrm{Cu}$ centers are oxidized with a paramagnetic $\mathrm{S}_{\text {tot }}=$ $1 / 2$ ground state, rendering it to be EPR and MCD active. Importantly, it has been established that the peroxide binding geometry in PA and PI are similar (e.g. both show the characteristic intense outer-shell peak in the EXAFS Fourier Transform data at $\sim 3.4 \AA$ ), demonstrating PA to be a valid structural analogue of PI. 41

In Figure 3, the 298K CD spectra of PI and PA and 4.2 K MCD spectrum of PA in the ligand field region are presented, where band positions are indicated based on previous simultaneous Gaussian fitting results using absorption, CD, and MCD (for PA) spectra. ${ }^{31,41}$ Four bands are observed in the PA MCD spectrum that are all associated with the paramagnetic $\mathrm{T} 2 \mathrm{Cu}^{\mathrm{II}}$ center, the $\mathrm{S}=1 / 2$ spin being localized at the $\mathrm{T} 2 \mathrm{Cu}^{\mathrm{II}}$ center in PA as previously determined by the EPR data. ${ }^{41}$ Alternatively, at least five bands are observed in the PA CD spectrum. Previously, these CD bands were assigned to the T3 Cu's by analogy to the resting oxidized enzyme where only the T3 Cu's contribute to the CD spectrum. However, it is now established that the structure of PA is significantly different from that of the resting oxidized enzyme (Figure 1) as the $\mathrm{T} 3 \mathrm{OH}^{-}$bridge of the resting enzyme is replaced by the peroxide in PA (and PI, Figure 
2(b)). Thus, it is possible that both the T2 and T3 Cu's contribute to the CD spectrum of PA. In fact, two bands are found in both the $\mathrm{CD}$ and MCD spectra of PA, at $\sim 12000 \mathrm{~cm}^{-1}$ and $\sim 17000 \mathrm{~cm}^{-1}$ (Figures 3(b) and (c)), indicating that these are associated with the $\mathrm{T} 2 \mathrm{Cu}$ site.

Comparing the CD spectra of PI and PA, four bands can be correlated to one another by their signs, energies, and intensities; the shifts in energies would derive from the differences in the electronic distributions in PI and PA. Importantly, the two PA CD bands associated with the T2 center, (+)12000 $\mathrm{cm}^{-1}$ and (-) $17000 \mathrm{~cm}^{-1}$, can be correlated to the PI CD bands at (+) $13300 \mathrm{~cm}^{-1}$ and (-) $15900 \mathrm{~cm}^{-1}$, respectively. The other PI CD bands, each of which correlates to a PA CD band, would then be associated with the other oxidized $\mathrm{Cu}$ center in PI (i.e. $\mathrm{T} 3_{\mathrm{B}}$ ). Notably, there is a PA CD band at $\sim(+) 14500 \mathrm{~cm}^{-1}$ that does not correlate to any band in the PI CD and PA MCD spectra. This band would be associated with the $\mathrm{T} 3_{\mathrm{A}}$ center, which is reduced in PI (Figure 2(b)) and MCD-silent in PA.

With the validation that the description of the metal oxidation states in PI is consistent with experiment (with $\mathrm{T} 2$ and $\mathrm{T} 3_{\mathrm{B}}$ oxidized and $\mathrm{T} 3_{\mathrm{A}}$ reduced), the diamagnetic $\mathrm{S}_{\text {tot }}=0$ ground state can now be correlated to the calculated electronic structure of PI. As mentioned above, the isotropic exchange coupling constant $J$ is calculated to be $-670 \mathrm{~cm}^{-1}$, indicative of a strong antiferromagnetic coupling between the spins at the two magnetic centers now considered to be the oxidized $\mathrm{T} 2$ and $\mathrm{T} 3_{\mathrm{B}}$ centers that are bridged by the peroxide. Figure 4 presents the contours of the $\alpha$ - and $\beta$-LUMOs that are based on T2 $\mathrm{Cu} \mathrm{d}_{\mathrm{x}}{ }^{2}-\mathrm{y}^{2}$ and $\mathrm{T} 3_{\mathrm{B}} \mathrm{Cu} \mathrm{d}_{\mathrm{x}}{ }^{2}-\mathrm{y}^{2}$, respectively, which represent the two magnetic orbitals involved in the superexchange interaction in PI (Figure 2(b)). Both of these magnetic orbitals contain a significant amount of $\mathrm{O}_{2}{ }^{2-} \pi_{\sigma}{ }^{*}$ character. As shown in Figure 4, the $\mathrm{O}_{2}{ }^{2-} \pi_{\sigma} *$ orbital is involved in an asymmetric orbital interaction with the $\mathrm{T} 2$ and $\mathrm{T} 3{ }_{\mathrm{B}} \mathrm{Cu}$ centers, in which the $\mathrm{O}_{2}{ }^{2-} \pi_{\sigma}$ * orbital forms one $\sigma$-bond with the $\mathrm{T} 2 \mathrm{Cu} \mathrm{d}_{\mathrm{x}}{ }^{2}-\mathrm{y}^{2}$ orbital in the T2-based magnetic orbital (Figure 4(a)), while it forms two $\sigma$-bonds with the $\mathrm{T}_{\mathrm{B}} \mathrm{Cu} \mathrm{d} \mathrm{C}_{\mathrm{x}}-\mathrm{y}^{2}$ orbital in the $\mathrm{T} 3_{\mathrm{B}}$-based magnetic orbital (Figure 4(b)).55 Importantly, the $\mathrm{O}_{2}{ }^{2-} \pi_{\sigma}{ }^{*}$ character allows good orbital overlap between $\mathrm{T} 2$ and $\mathrm{T} 3_{\mathrm{B}}$-based magnetic orbitals at the bridging peroxide, which leads to the strong antiferromagnetic coupling in PI.

The calculated electronic structure of PI can also be correlated to the spectral features in the charge transfer (CT) region of the absorption spectrum of PI. In Figure 5(a), the absorption spectrum of PI of T1HgLc is presented in red, where positions of the four CT bands associated with $\mathrm{O}_{2}{ }^{2-} \rightarrow \mathrm{Cu}^{\mathrm{II}} \mathrm{CT}$ transitions are indicated based on previous studies of PI in both the T1HgLc and T1D Fet3p. ${ }^{31,34}$ The four bands can be categorized into the higher energy/higher intensity $\mathrm{O}_{2}{ }^{2-} \pi_{\sigma}{ }^{*} \rightarrow \mathrm{Cu}^{\mathrm{II}}\left(\sim 31000 \mathrm{~cm}^{-1}\right.$ and $\left.\sim 27500 \mathrm{~cm}^{-1}\right)$ and lower energy/lower intensity $\mathrm{O}_{2}{ }^{2-} \pi_{\mathrm{v}}{ }^{*} \rightarrow \mathrm{Cu}^{\mathrm{II}} \mathrm{CT}$ transitions $\left(25000 \mathrm{~cm}^{-1}\right.$ and $\left.\sim 21000 \mathrm{~cm}^{-1}\right)$. Further distinction between the two $\mathrm{O}_{2}{ }^{2-} \pi_{\sigma}{ }^{*} \rightarrow \mathrm{Cu}^{\mathrm{II}} \mathrm{CT}$ transitions can be made using the MO description of PI in Figure 4. The T2-based $\alpha \mathrm{LUMO}$ and $\mathrm{T} 3_{\mathrm{B}}$-based $\beta$ LUMO, both of which are significantly mixed with the $\mathrm{O}_{2}{ }^{2-} \pi_{\sigma} *$ orbital, would be good acceptor MOs for the $\mathrm{O}_{2}{ }^{2-} \pi_{\sigma} * \rightarrow \mathrm{Cu}^{\mathrm{II}} \mathrm{CT}$ transitions, the donor MO being the doubly-occupied MO based on $\mathrm{O}_{2}{ }^{2-} \pi_{\sigma}{ }^{*}$. The MO energies and $\mathrm{O}_{2}{ }^{2-}$

$\pi_{\sigma} *$ characters in these LUMOs can be directly correlated to the relative energies and intensities of the $\mathrm{O}_{2}{ }^{2-} \pi_{\sigma}{ }^{*} \rightarrow \mathrm{Cu}^{\mathrm{II}} \mathrm{CT}$ transitions. As shown in Figure 4, the $\mathrm{T} 3_{\mathrm{B}}$-based $\beta \mathrm{LUMO}$ is higher in energy than the T2-based $\alpha$ LUMO by $0.42 \mathrm{eV}\left(\sim 3400 \mathrm{~cm}^{-1}\right)$ and the peroxide character is higher by $\sim 11 \%$ (the difference of the $\%$ character of both peroxide $\mathrm{O}$ atoms). Based on these descriptions, the higher energy band at $\sim 31000 \mathrm{~cm}^{-1}$ can be assigned to the $\mathrm{O}_{2}{ }^{2-} \pi_{\sigma}{ }^{*} \rightarrow \mathrm{T} 3_{\mathrm{B}}$ CT transition and the lower energy band at $\sim 27500 \mathrm{~cm}^{-1}$ to the $\mathrm{O}_{2}{ }^{2-} \pi_{\sigma}{ }^{*} \rightarrow \mathrm{T} 2 \mathrm{CT}$ transition. 56 Similar assignments can be applied to the other lower energy CT bands, the $\mathrm{O}_{2}{ }^{2-} \pi_{\mathrm{v}}{ }^{*} \rightarrow \mathrm{T} 3_{\mathrm{B}}$ and T2 CT transitions, as indicated in Figure 5(a, red).

To further validate the above CT assignments in PI, the CT spectral features of PI are compared to those of PA. In Figure 5, the $298 \mathrm{~K}$ absorption (in black) and 4.2 K MCD spectra of PA are 
presented with band positions from previous study. ${ }^{41}$ As mentioned above, the features of the PA MCD spectrum are only associated with its paramagnetic T2 site. Of the several bands observed in the PA MCD spectrum, a definitive assignment was previously made for the intense (+) $25500 \mathrm{~cm}^{-1}$ band as a $\mathrm{O}_{2}{ }^{2-} \rightarrow \mathrm{T} 2 \mathrm{CT}$ transition based on comparative analysis of absorption, $\mathrm{CD}$, and MCD spectra. ${ }^{41}$ From pulsed EPR data, the T2 water-derived ligand is $\mathrm{OH}^{-}$in PA. 57 Due to the differences in ligand field, the T2-based acceptor MO in PA would be several thousand $\mathrm{cm}^{-1}$ higher than that of $\mathrm{PI}$ with $\mathrm{H}_{2} \mathrm{O}$ as its $\mathrm{T} 2$ water-derived ligand. Indeed, the $\mathrm{O}_{2}{ }^{2-} \pi_{\mathrm{v}}{ }^{*} \rightarrow \mathrm{T} 2 \mathrm{CT}$ transition in PI (Figure $5\left(\mathrm{a}\right.$, red), at $\sim 21000 \mathrm{~cm}^{-1}$ ) is found $\sim 4000 \mathrm{~cm}^{-1}$ lower in energy than the $25500 \mathrm{~cm}^{-1}$ band in PA. Similarly, it is expected that the $\mathrm{O}_{2}{ }^{2-}$ $\pi_{\sigma}{ }^{*} \rightarrow \mathrm{T} 2 \mathrm{CT}$ transition in PA is higher in energy by $\sim 4000 \mathrm{~cm}^{-1}$ than that of PI observed at $\sim 27500 \mathrm{~cm}^{-1}$. The $\sim 31000 \mathrm{~cm}^{-1}$ band in PA can thus be assigned as the $\mathrm{O}_{2}{ }^{2-} \pi_{\sigma}{ }^{*} \rightarrow \mathrm{T} 2 \mathrm{CT}$ transition, which is supported by the fact that it is observed in both the absorption and MCD spectra of PA.

\section{B. O-O Bond Cleavage}

With an experimentally calibrated description of the geometric and electronic structure of PI, we now extend our investigation towards correlating PI with NI to describe the O-O bond cleavage reaction by the trinuclear $\mathrm{Cu}$ cluster in the MCOs. As mentioned in the Introduction, experiment indicates that PI is a kinetically competent precursor of the four-electron $\mathrm{O}_{2}$ reduced NI and that the $\mathrm{PI} \rightarrow \mathrm{NI}$ process is the second two-electron step in the reaction mechanism that involves the $\mathrm{O}-\mathrm{O}$ bond cleavage. This step is very fast in the native enzyme $\left(k>350 \mathrm{~s}^{-1}\right), 23,36$ where an extra electron from $\mathrm{T} 1$ promotes the two-electron peroxide O-O bond cleavage. Notably, it also occurs during the decay of PI, which is slow $(k \sim 0.0003-0.003$ $\mathrm{s}^{-1}$ ) due to the lack of the T1 site as the nominal source of the fourth electron.

Thus, we have modeled our starting geometry for O-O cleavage to NI with the PI structure obtained above (Figure 2(b)). In addition to the formate ion that mimics $\mathrm{D}_{94}$, a formic acid was included to mimic the role of a second nearby carboxylate residue, $\mathrm{E}_{487}$ (Figure 1). From a recent Fet3p mutant study, $\mathrm{E}_{487}$ has been demonstrated to play a central role in proton donation in the decay of PI. ${ }^{37}$ Moreover, the proton from $\mathrm{E}_{487}$ would be necessary to form the $\mathrm{OH}^{-}$ bridge in NI. For the simplicity of the model, the position of the formic acid was moved closer to the $\mathrm{T} 3$ site than in the enzyme structure. In the crystal structures of resting MCOs, $\mathrm{E}_{487}$ (or the equivalent $\mathrm{Asp} / \mathrm{Glu}$ ) is hydrogen bonded to the $\mathrm{T} 3 \mathrm{OH}^{-}$bridging ligand through one or two water molecules. Here, the mediating water was removed and the formic acid was placed such that the $\mathrm{O}$ atom of the formic acid involved in the hydrogen bonding (designated $\mathrm{O}^{\prime}$, see Figure 6 , inset) is at the position of the $\mathrm{O}$ atom of the removed water molecule. In addition, unless otherwise mentioned, the distance between the peroxide $\mathrm{O}$ atom (designated $\mathrm{O}^{2}$, see Figure 6 , inset) and the formic acid $\mathrm{O}^{\prime}$ atom was fixed at a value of $2.87 \AA$, which is a reasonable distance for the hydrogen bond $\left(2.87 \AA\right.$ is the distance between the $\mathrm{O}$ atoms of $\mathrm{T} 3 \mathrm{OH}^{-}$bridging ligand and the mediating water molecule in the crystal structure of resting $T$. $v$. laccase, from which the starting geometries for all of the calculations of this study have been obtained). ${ }^{58}$

i. PI with an Extra Electron from T1: $\mathrm{PI}+\mathrm{e}-\mathrm{At}$ the starting point of $\mathrm{O}-\mathrm{O}$ bond cleavage, the extra electron from the T1 site is assumed to have been transferred to the PI structure, while the proton on the formic acid (designated $\mathrm{H}^{\prime}$, see Figure 6, inset) is not transferred. The resulting structure, designated PI+e, is shown in Figure 6. Notably, the structure of PI+e is considerably different from that of PI (Figure 2(b)). This structure derives from the occupation of the extra electron in the hole on the T2 center in PI (i.e. occupation of the $\alpha$ LUMO in Figure 4), which was found to be lower in MO energy than the hole on the $\mathrm{T}_{\mathrm{B}}$ center in PI (the $\beta$ LUMO in Figure 4). Due to the reduction of the T2 center, the T2-peroxide bonding interaction is lost, and consequently, PI+e acquires a structure with the peroxide atom in between $\mathrm{T} 3_{\mathrm{B}}$ and $\mathrm{T} 3_{\mathrm{A}}$ centers. The $\mathrm{T} 3_{\mathrm{A}}$-peroxide bonding interaction, however, is found to be very limited as the 
$\mathrm{T} 3_{\mathrm{A}}$ is also reduced, which is indicated by the low spin density on the $\mathrm{T} 3_{\mathrm{A}}$ center (spin densities are $\mathrm{T} 2=0.00, \mathrm{~T} 3_{\mathrm{A}}=+0.07, \mathrm{~T} 3_{\mathrm{B}}=+0.48$ in $\left.\mathrm{PI}+\mathrm{e}\right)$.

ii. Proton-Unassisted O-O Bond Cleavage-The energy changes along the peroxide $\mathrm{O}^{1}-\mathrm{O}^{2}$ bond elongation (see Figure 6, inset for atom designations) without proton transfer from the formic acid was investigated first. In addition to PI+e with $\mathrm{R}\left(\mathrm{O}^{1}-\mathrm{O}^{2}\right)=1.46 \AA$, partially optimized PI+e structures with fixed $\mathrm{R}\left(\mathrm{O}^{1}-\mathrm{O}^{2}\right)=1.50,1.60,1.70,1.80$, and $1.90 \AA$ were obtained. At $\mathrm{R}\left(\mathrm{O}^{1}-\mathrm{O}^{2}\right)>1.90 \AA$, the proton transfer from the formic acid to the $\mathrm{O}^{2}$ atom occurred spontaneously due to the increased negative charge on the $\mathrm{O}^{2}$ center. Finally, the NI structure with $\mathrm{O}^{2}$ protonated (i.e. the $\mathrm{T} 3 \mathrm{OH}^{-}$bridge in $\mathrm{NI}$ ) was obtained at $\mathrm{R}\left(\mathrm{O}^{1}-\mathrm{O}^{2}\right) \approx 2.40$ $\AA$. All optimizations were performed at the broken-symmetry states as the spin expectation value, $\left\langle\mathrm{S}^{2}\right\rangle$, deviated from the pure spin doublet value of $\left\langle\mathrm{S}^{2}\right\rangle \approx 0.75$ upon O-O bond elongation and spin redistribution among the $\mathrm{Cu}$ and peroxide $\mathrm{O}$ atoms. Two broken-symmetry spin configurations allow description of transient states along the $\mathrm{O}-\mathrm{O}$ bond elongation as two electrons of opposite spins ( $\uparrow$ and $\downarrow$ ) are donated from the reduced $\mathrm{T} 2$ and $\mathrm{T} 3_{\mathrm{A}}$ centers to the $\mathrm{O}_{2}{ }^{2-} \sigma^{*}$ orbital in PI+e, $\left|\mathrm{T} 2 \mathrm{~T} 3_{\mathrm{A}} \mathrm{T} 3_{\mathrm{B}}\right\rangle=|\beta \alpha \alpha\rangle$ and $|\alpha \beta \alpha\rangle$. Of these, however, it was found that only the $\mid \beta \alpha \alpha>$ spin configuration generates transient state structures that describe continuous structural transition between PI+e and NI. In the $\mid \beta \alpha \alpha>$ spin configuration, the same spin orientation on the two $\mathrm{T} 3 \mathrm{Cu}$ centers allows favorable electron delocalization over the $\mathrm{T} 3$ centers via the bridging $\mathrm{O}^{1}$ and $\mathrm{O}^{2}$ atoms. As a result, the $\mathrm{O}^{1}$ and $\mathrm{O}^{2}$ atoms remained bound to both the $\mathrm{T} 3_{\mathrm{A}}$ and $\mathrm{T} 3_{\mathrm{B}}$ centers $\left(\mathrm{O}^{1}\right.$ also bound to $\left.\mathrm{T} 2\right)$ and the $\mathrm{O}-\mathrm{O}$ bond elongation occurred along the direction perpendicular to $\mathrm{T}_{\mathrm{A}}-\mathrm{T} 3_{\mathrm{B}}$ in the $\mathrm{Cu}_{3}$ plane, leading to the NI structure with $\mu_{3}$-oxo and $\mathrm{T} 3 \mu-\mathrm{OH}^{-}$bridging ligands. The $\mathrm{O}-\mathrm{O}$ bond elongation in the $\mid \alpha \beta \alpha>$ spin configuration, on the other hand, occurred along the direction perpendicular to $\mathrm{T} 2-\mathrm{T} 3_{\mathrm{B}}$ in the $\mathrm{Cu}_{3}$ plane, as the electron delocalization over the $\mathrm{T} 2$ and $\mathrm{T} 3_{\mathrm{B}}$ centers via the $\mathrm{O}^{1}$ atom resulted in the formation of a strong $\mathrm{T} 2-\mathrm{O}-\mathrm{T} 3_{\mathrm{B}}$ bridge with a wide bridging angle $>150^{\circ}$. This led to the dissociation of the $\mathrm{O}^{1}$ atom from the $\mathrm{T} 3{ }_{\mathrm{A}}$ center and consequently, the structures obtained with long $\mathrm{R}\left(\mathrm{O}^{1}-\mathrm{O}^{2}\right)(>1.8 \AA)$ did not correlate with the all-bridged structure of NI. ${ }^{59}$

The overall $\mathrm{PI}+\mathrm{e} \rightarrow \mathrm{NI}$ process is highly exothermic, with $\Delta \mathrm{E}=-51 \mathrm{kcal} / \mathrm{mol}$ (obtained from comparison of the pure spin doublet energies of PI+e and NI, where the doublet energy of NI was obtained from projection of the energy of the broken-symmetry state $\left|\mathrm{T} 2 \mathrm{~T} 3_{\mathrm{A}} \mathrm{T} 3_{\mathrm{B}}\right\rangle=1$ $\beta \alpha \alpha\rangle$ with $\left\langle S^{2}\right\rangle \sim 1.75$ ), indicating that this is a highly thermodynamically driven process. The transition state is located at $\mathrm{R}\left(\mathrm{O}^{1}-\mathrm{O}^{2}\right) \approx 1.70 \AA$ ( $\mathrm{TS}_{1}$, Figure 6 , top), with an activation energy estimated at $+5.9 \mathrm{kcal} / \mathrm{mol}$ relative to PI+e. The low activation energy from these calculations is consistent with the experimental value of $\sim 3-5 \mathrm{kcal} / \mathrm{mol}$, which is obtained from the experimental rate of $k>350 \mathrm{~s}^{-1}$ for $\mathrm{O}-\mathrm{O}$ bond cleavage, using the Arrhenius equation $k=\mathrm{A}$ exp $\left(-\mathrm{E}_{\mathrm{a}} / \mathrm{RT}\right)$, where the pre-exponential factor $\mathrm{A}$ is assumed to be in the order of $10^{5}-10^{6}$. Importantly, this result implies that a proton is not required to drive the catalytic O-O bond cleavage reaction in the MCOs, although it is required at a later stage $\left(\right.$ after $\mathrm{TS}_{1}$ ) to protonate the T3 $\mu$-oxo ligand, which otherwise would be energetically unfavorable.

iii. Proton-Assisted O-O Bond Cleavage-Alternatively, the effect of protonation on the $\mathrm{O}-\mathrm{O}$ bond cleavage reaction was investigated by transferring the $\mathrm{H}^{\prime}$ atom on the formic acid to the peroxide $\mathrm{O}^{2}$ atom. First, the structure of $\mathrm{PI}+\mathrm{e}$ after the complete proton transfer was obtained (PI+e+H, Figure 6, bottom). The overall geometry of PI+e+H is very similar to that of PI+e, although it is found to be at lower energy than PI+e by - $2.1 \mathrm{kcal} / \mathrm{mol}$. From this energy difference (neglecting entropy contributions), the $\mathrm{pK}_{\mathrm{a}}$ of PI+e can be estimated to be $\sim 1.5 \mathrm{pH}$ units higher than that of the proton donor (i.e. the formic acid in our model) at room temperature. Note also that the proton transfer in the $\mathrm{PI}+\mathrm{e} \rightarrow \mathrm{PI}+\mathrm{e}+\mathrm{H}$ process is likely a kinetically unhindered process. With the fixed $\mathrm{R}\left(\mathrm{O}^{2}-\mathrm{O}^{\prime}\right)=2.87 \AA$, it was estimated that the energy barrier for the proton transfer is $\sim 7.7 \mathrm{kcal} / \mathrm{mol}^{49}\left(\right.$ at $\mathrm{R}\left(\mathrm{O}^{2}-\mathrm{H}^{\prime}\right)=1.50 \AA, \mathrm{R}\left(\mathrm{O}^{1}-\mathrm{O}^{2}\right)=$ $1.46 \AA$ (fixed)). However, this activation energy was found to decrease with shorter $\mathrm{R}\left(\mathrm{O}^{2}-\mathrm{O}\right.$ 
'): At $\mathrm{R}\left(\mathrm{O}^{2}-\mathrm{O}^{\prime}\right)=2.75 \AA$ (fixed), the estimated activation energy is lowered to $\sim 3.9 \mathrm{kcal} / \mathrm{mol}$ (at $\mathrm{R}\left(\mathrm{O}^{2}-\mathrm{H}^{\prime}\right)=1.40 \AA$ and $\mathrm{R}\left(\mathrm{O}^{1}-\mathrm{O}^{2}\right)=1.46 \AA$ (fixed); Table $\left.\mathrm{S} 4\right)$, while at $\mathrm{R}\left(\mathrm{O}^{2}-\mathrm{O}^{\prime}\right)=2.60 \AA$ (fixed), no energy barrier was found (i.e. optimization of PI+e resulted in PI+e+H). Therefore, the activation barrier for the proton transfer is largely dependent on the heavy atom distances, and in the flexible protein environment, the $\mathrm{O}$ atom distances would be dynamically optimized to accommodate the lower activation barrier for proton transfer to convert PI+e to the thermodynamically more stable $\mathrm{PI}+\mathrm{e}+\mathrm{H}$ form. This would be consistent with the enzyme where the proton transfer would be mediated by a water molecule between $\mathrm{E}_{487}$ and the peroxide.

The energy changes along the $\mathrm{O}^{1}-\mathrm{O}^{2}$ bond elongation in the $\mathrm{PI}+\mathrm{e}+\mathrm{H}$ structure were then investigated. In addition to $\mathrm{PI}+\mathrm{e}+\mathrm{H}$ with $\mathrm{R}\left(\mathrm{O}^{1}-\mathrm{O}^{2}\right)=1.45 \AA$, partial optimizations of $\mathrm{PI}+\mathrm{e}+\mathrm{H}$ were performed at fixed $\mathrm{R}\left(\mathrm{O}^{1}-\mathrm{O}^{2}\right)$ of $1.50,1.60,1.70,1.80,1.90$, and $2.10 \AA$ (plus NI with $\mathrm{R}$ $\left(\mathrm{O}^{1}-\mathrm{O}^{2}\right) \approx 2.40 \AA$ ). As with PI+e, the broken-symmetry spin configuration of $\left|\mathrm{T} 2 \mathrm{~T} 3_{\mathrm{A}} \mathrm{T} 3_{\mathrm{B}}\right\rangle=$ $|\beta \alpha \alpha\rangle$ was implemented in these calculations (vide supra). Assuming that the activation barrier of the proton transfer $(\mathrm{PI}+\mathrm{e} \rightarrow \mathrm{PI}+\mathrm{e}+\mathrm{H})$ is low,, 00 the transition state for the $\mathrm{PI}+\mathrm{e} \rightarrow \mathrm{PI}+\mathrm{e}+\mathrm{H} \rightarrow \mathrm{NI}$ process is located at $\mathrm{R}\left(\mathrm{O}^{1}-\mathrm{O}^{2}\right) \approx 1.70 \AA\left(\mathrm{TS}_{2}\right.$, Figure 6 , bottom), where the activation energy is estimated $+3.3 \mathrm{kcal} / \mathrm{mol}$ relative to $\mathrm{PI}+\mathrm{e}$ and $+5.4 \mathrm{kcal} / \mathrm{mol}$ relative to $\mathrm{PI}+\mathrm{e}+\mathrm{H}$. As with PI $+e$, the low energy barrier for this process is consistent with the experimental value of $\sim 3-5$ $\mathrm{kcal} / \mathrm{mol}$. Although not by much, the activation energy is smaller than that of the protonunassisted $\mathrm{PI}+\mathrm{e} \rightarrow \mathrm{NI}$ process, indicating that the proton does play a role in the cleavage of the $\mathrm{O}-\mathrm{O}$ bond.

iv. 2D-Potential Energy Surface: Two Possible Reaction Pathways-The protonunassisted $\mathrm{PI}+\mathrm{e} \rightarrow \mathrm{NI}$ and proton-assisted $\mathrm{PI}+\mathrm{e} \rightarrow \mathrm{PI}+\mathrm{e}+\mathrm{H} \rightarrow \mathrm{NI}$ processes can be combined into a two-dimensional potential energy surface (2D-PES), which simultaneously accounts for the $\mathrm{R}\left(\mathrm{O}^{1}-\mathrm{O}^{2}\right)$ and $\mathrm{R}\left(\mathrm{O}^{2}-\mathrm{H}^{\prime}\right)$ reaction coordinates. The surface was generated using the 28 points at different $\mathrm{R}\left(\mathrm{O}^{1}-\mathrm{O}^{2}\right)$ and $\mathrm{R}\left(\mathrm{O}^{2}-\mathrm{H}^{\prime}\right)$ : at $\mathrm{R}\left(\mathrm{O}^{1}-\mathrm{O}^{2}\right)=1.46,1.50,1.60,1.70 \AA$ (i.e. up to $\mathrm{TS}_{1}$ and $\left.\mathrm{TS}_{2}\right), \mathrm{R}\left(\mathrm{O} 2-\mathrm{H}^{\prime}\right)=\sim 1.85,1.70,1.50,1.30, \sim 1.0 \AA$; at $\mathrm{R}\left(\mathrm{O}^{1}-\mathrm{O}^{2}\right)=1.80$ and $1.90 \AA, \mathrm{R}\left(\mathrm{O}^{2}-\mathrm{H}^{\prime}\right)=$ $\sim 1.8,1.50, \sim 1.0 \AA$; at $\mathrm{R}\left(\mathrm{O}^{1}-\mathrm{O}^{2}\right)=2.10$ and $2.40 \AA, \mathrm{R}\left(\mathrm{O}^{2}-\mathrm{H}^{\prime}\right)=\sim 1.0 \AA$. The results are given in Table S3.

Starting from the rear diagonal in Figure 7, which is PI+e, and proceeding to the front diagonal, which is NI, two possible lowest-energy paths can be traced on the 2D-PES that are consistent with the proton-unassisted process (path 1: $\mathrm{PI}+\mathrm{e} \rightarrow \mathrm{TS}_{1} \rightarrow \mathrm{NI}$ ) and the proton-assisted process (path 2: $\mathrm{PI}+\mathrm{e} \rightarrow \mathrm{PI}+\mathrm{e}+\mathrm{H} \rightarrow \mathrm{TS}_{2} \rightarrow \mathrm{NI}$ ). Recall that previous kinetic studies on PI decay in T1HgLc ${ }^{23}$ and T1D Fet3p $\mathrm{p}^{34,35,37}$ have shown that an inverse proton kinetic isotope effect $\left(k_{H} / k_{D}=0.89\right)$ is involved at low $\mathrm{pH}(\mathrm{pH} \sim 5)$, while no isotope effect is present $\left(k_{H} / k_{D} \approx 1\right)$ at high $\mathrm{pH}(\mathrm{pH} \sim 7)$. These kinetic isotope data suggest that the $\mathrm{O}-\mathrm{H}$ bond from protonation of the peroxide must be present at the transition state at low $\mathrm{pH}$, while it is not formed at the transition state at high $\mathrm{pH} .{ }^{37}$ Thus, the distinct kinetic descriptions of PI decay at different pH's can be directly correlated to path 1 and 2 in the 2D-PES presented in Figure 7. In addition, the similarity in the activation energies of the proton-unassisted and proton-assisted processes of path 1 and $2(5.7 \mathrm{kcal} / \mathrm{mol} \mathrm{vs} .5 .4 \mathrm{kcal} / \mathrm{mol})$ is also consistent with the similarity in the experimental activation energy of PI decay at high and low $\mathrm{pH}$, which only differ by $\sim 1 \mathrm{kcal} /$ mol. 23

v. Molecular Orbital Description of the O-O Bond Cleavage-Examination of the electronic structure changes along the reaction coordinate provides detailed insight into the orbital contributions to the $\mathrm{O}-\mathrm{O}$ bond cleavage reaction mechanism.

First, the spin density changes at the $\mathrm{Cu}$ centers in $\mathrm{PI}+\mathrm{e}$ and $\mathrm{PI}+\mathrm{e}+\mathrm{H}$ upon elongation of the $\mathrm{O}^{1}-\mathrm{O}^{2}$ bonds are shown in Figure 8 . The spin density at the $\mathrm{T}_{\mathrm{B}}$ center remains constant throughout the reaction coordinate, indicating that this center remains fully oxidized. 
Alternatively, the magnitudes of the spin densities at the $\mathrm{T} 2$ and $\mathrm{T} 3_{\mathrm{A}}$ centers gradually increase upon elongation of the $\mathrm{O}^{1}-\mathrm{O}^{2}$ bond, demonstrating that the reduced $\mathrm{T} 2$ and $\mathrm{T}_{\mathrm{A}}$ centers gradually donate electrons in the reductive cleavage of the peroxide. Notably, the T2 and $\mathrm{T}_{\mathrm{A}}$ spin densities increase symmetrically with opposite signs, reaching $\sim 30-50 \%$ of their full values at $\mathrm{NI}$, where these $\mathrm{Cu}$ centers are fully oxidized. This implies that that the $\mathrm{O}-\mathrm{O}$ bond cleavage is a simultaneous two-electron process.

The MOs that are involved in the two-electron $\mathrm{O}-\mathrm{O}$ bond cleavage process in $\mathrm{PI}+\mathrm{e}$ $+\mathrm{H} \rightarrow \mathrm{TS}_{2} \rightarrow \mathrm{NI}$ are shown in Figure 9 (a similar description can be applied to the PI $+\mathrm{e} \rightarrow \mathrm{TS}_{1} \rightarrow \mathrm{NI}$ process). According to the frontier molecular orbital (FMO) theory, the reaction is activated by good overlap between the HOMO of the donor (i.e. the reduced T2 and T3 $\mathrm{A}$ $\mathrm{Cu}^{\prime} \mathrm{s}$ ) and the LUMO of the acceptor (i.e. the peroxide $\sigma^{*}$ ). At the start of the process, the two electrons of the donor T2 and T3 $3_{\mathrm{A}}$ occupy the $\alpha$ - and $\beta$-HOMOs of PI+e+H (Figure 9 , left), while the unoccupied $\mathrm{O}_{2}{ }^{2-} \sigma^{*}$ is at high energy. As the $\mathrm{O}-\mathrm{O}$ bond is elongated, the unoccupied $\mathrm{O}_{2}{ }^{2-} \sigma^{*}$ decreases in energy and starts mixing with both the donor $\mathrm{T} 2 \mathrm{~d}_{\mathrm{x}}{ }^{2-\mathrm{y}^{2}}$ and $\mathrm{T} 3 \mathrm{~A}_{\mathrm{A}} \mathrm{d}_{\mathrm{x}}{ }^{2}-\mathrm{y}^{2}$ HOMOs (Figure 9, middle). The strong orbital mixing at the transition state represents the efficiency of electron transfer from the donor $\mathrm{T} 2$ and $\mathrm{T} 3{ }_{\mathrm{A}}$ HOMOs to the acceptor peroxide LUMO, which is consistent with the low energy barrier.

After the transition state, the electrons are fully transferred from the $\mathrm{T} 2$ and $\mathrm{T} 3_{\mathrm{A}} \mathrm{Cu}$ centers to both $\mathrm{O}$ atoms of the peroxide (i.e. fully oxidizing $\mathrm{T} 2$ and $\mathrm{T} 3_{\mathrm{A}}$ and fully reducing $\mathrm{O}_{2}$ ), completing the $\mathrm{O}-\mathrm{O}$ bond cleavage (Figure 9 , right). As described previously, the two $\mathrm{O}$ atoms become the $\mu_{3}$-oxo and $\mathrm{T} 3 \mu-\mathrm{OH}^{-}$bridging ligands in NI that contribute significantly in stabilizing NI structure providing the thermodynamic driving force for the four-electron reduction of $\mathrm{O}_{2}$ in the MCOs. ${ }^{25,27,28}$ It is worth mentioning that while it was necessary to impose $\left|\mathrm{T} 2 \mathrm{~T} 3_{\mathrm{A}} \mathrm{T} 3_{\mathrm{B}}\right\rangle=|\beta \alpha \alpha\rangle$ spin configuration to generate the transient state structures relevant to the $\mathrm{PI}+\mathrm{e} / \mathrm{PI}+\mathrm{e}+\mathrm{H} \rightarrow \mathrm{NI}$ process (vide supra), three broken-symmetry states $|\alpha \alpha \beta\rangle, \mid$ $\alpha \beta \alpha>$ and $\mid \beta \alpha \alpha>$, equally contribute to the ground state of NI. This is due to the favorable superexchange interactions among all three $\mathrm{Cu}$ centers via the $\mu_{3}$-oxo and $\mathrm{T} 3 \mu-\mathrm{OH}^{-}$bridging ligands upon oxidation of the $\mathrm{T} 2$ and $\mathrm{T}_{3}$ centers (the second $\mathrm{T} 3 \mu-\mathrm{OH}^{-}$bridging ligand was found necessary to keep the three exchange coupling constants similar in NI, due to the difference in ligand environments between T2 and T3 sites ${ }^{28}$ ). Importantly, the interaction of the three broken-symmetry states results in the spin-frustrated ground state of NI. The unique properties of the ground state of NI are evidenced by features in its EPR and MCD spectra, where a low g-value $<2.0$ and a low-lying doublet excited state at $\sim 150 \mathrm{~cm}^{-1}$ have been observed that are not possible for typical $\mathrm{Cu}(\mathrm{II})$ complexes. ${ }^{18}$

\section{Discussion}

Despite the strong experimental evidence that PI is the precursor for $\mathrm{NI}$ in the reaction mechanism of the MCOs, the geometric and electronic structure of PI has been elusive. It has been considered that the two-electron transfer to $\mathrm{O}_{2}$ in the formation of PI occurs from the two $\mathrm{T} 3 \mathrm{Cu}$ 's, in analogy to $\mathrm{O}_{2}$ binding reactions in the other binuclear $\mathrm{Cu}$ sites in biology $(\mathrm{Hc}$ and Tyr). However, the T3 sites of MCO and Hc/Tyr are intrinsically different. ${ }^{38-40,53,54,61}$ In particular, the T3 site in the T2-depleted form of tree Lc has been shown to lack any $\mathrm{O}_{2}$ reactivity. ${ }^{52-54}$ Interestingly, although the His ligand conformations are different in the T3 sites of MCOs and $\mathrm{Hc} / \mathrm{Tyr}$, our calculations on PI without $\mathrm{D}_{94}$ resulted in the side-on bridged geometry that is very similar to those of the oxy-Hc and oxy-Tyr (Figure 2(a)). This suggests that the description of the trinuclear $\mathrm{Cu}$ cluster site must include the additional effects of the second-coordination sphere residues, in particular, $\mathrm{D}_{94}$.

Inclusion of the $\mathrm{D}_{94}$ residue in our models allowed us to obtain the spectroscopically relevant $\mu_{3}-1,1,2$ bridged PI structure. Recent studies with Fet3p mutants have implicated the important 
role of the $\mathrm{D}_{94}$ residue, ${ }^{23,31,34,35}$ where mutation of this residue to the uncharged Ala or Asn residue results in a complete loss of $\mathrm{O}_{2}$ reactivity, while its mutation into the negatively charged Glu retains the $\mathrm{O}_{2}$ reactivity. ${ }^{35,37}$ This suggests that the negative charge at the $\mathrm{D}_{94}$ position must induce a unique charge distribution in the trinuclear $\mathrm{Cu}$ cluster site that is necessary to stabilize the PI structure. Our calculations show that the inclusion of the negatively charged $\mathrm{D}_{94}$ results in the oxidation of the $\mathrm{T} 2$ and $\mathrm{T} 3_{\mathrm{B}}$ centers with the $\mathrm{T} 3_{\mathrm{A}}$ center reduced. Importantly, the $\mu_{3}-1,1,2$ bridged geometry of PI would be closely related to the role of the trinuclear $\mathrm{Cu}$ cluster active site in biology, which is to irreversibly bind $\mathrm{O}_{2}$ and activate it for the second two-electron step in the four-electron reduction of $\mathrm{O}_{2}$ to $\mathrm{H}_{2} \mathrm{O}$. This is in contrast to the role of oxy-Hc with its side-on bridged geometry, which is to reversibly bind and release $\mathrm{O}_{2}$.

Evaluation of the PI+e $\rightarrow$ NI process using the 2D-PES (Figure 7) has provided insight into the rapid $\mathrm{O}-\mathrm{O}$ bond cleavage process in the MCOs. Firstly, the reaction would be driven by the large thermodynamic driving force $(\Delta \mathrm{E}=-51 \mathrm{kcal} / \mathrm{mol}$, NI relative to $\mathrm{PI}+\mathrm{e})$ derived from the stable NI structure (relative to PI+e). The large exothermicity promotes the low energy barrier of the $\mathrm{O}-\mathrm{O}$ bond cleavage process, which was calculated to be $\sim 5-6 \mathrm{kcal} / \mathrm{mol}$, consistent with the experimental value of 3-5 kcal/mol. Moreover, the spin density changes along the two possible reaction paths found in the 2D-PES (Figure 8) indicate that the two-electron reduction of the peroxide in the $\mathrm{O}-\mathrm{O}$ bond cleavage proceeds via a simultaneous two-electron process and not two sequential one-electron steps. This is consistent with the fact that the driving force of one-electron transfer from the T2/T3 Cu's $\left(\mathrm{E}^{0} \sim 0.4 \mathrm{~V}\right)$ to peroxide is low $\left(\mathrm{E}^{0}=+0.38 \mathrm{~V}\right.$ vs. NHE for $\mathrm{H}_{2} \mathrm{O}_{2}+\mathrm{H}^{+}+\mathrm{e}^{-} \rightarrow \mathrm{OH}+\mathrm{H}_{2} \mathrm{O}$ at $\mathrm{pH}$ 7.0), while that of two-electron transfer is high $\left(\mathrm{E}^{0}=+1.35 \mathrm{~V}\right.$ vs. NHE for $\mathrm{H}_{2} \mathrm{O}_{2}+2 \mathrm{H}^{+}+2 \mathrm{e}^{-} \rightarrow 2 \mathrm{H}_{2} \mathrm{O}$ at $\mathrm{pH}$ 7.0). 62 Notably, this provides complementary evidence in support of the experimental results that $\mathrm{NI}$ is not a three-electron reduced oxygen intermediate as previously proposed but rather a four-electron product. ${ }^{19}$, $20,63-65$

The efficient $\mathrm{O}-\mathrm{O}$ bond cleavage is also closely related to the triangular topology of the trinuclear $\mathrm{Cu}$ cluster. In the transition states (i.e. $\mathrm{TS}_{1}$ and $\mathrm{TS}_{2}$ ), the triangular arrangement of the $\mathrm{Cu}$ centers allows the acceptor $\mathrm{O}_{2}{ }^{2-} \sigma^{*} \mathrm{MO}$ to have strong $\sigma$-overlaps with both the donor $\mathrm{T} 2$ and $\mathrm{T} 3{ }_{\mathrm{A}} \mathrm{d}_{\mathrm{x}}{ }^{2}-\mathrm{y}^{2}$ MOs (Figure 10) that promote facile two electron donation and the low activation barrier. Furthermore, it is worth mentioning that while the $\mathrm{T} 3_{\mathrm{B}}$ center does not contribute directly in electron donation to $\mathrm{PI}$, this positively charged oxidized $\mathrm{Cu}^{\mathrm{II}}$ center would contribute in lowering the $\mathrm{O}_{2}{ }^{2-} \sigma^{*}$ energy. The orbital mixing of the half-occupied $\mathrm{d}_{\mathrm{x}}{ }^{2}-\mathrm{y}^{2}$ orbital of the oxidized $\mathrm{T}_{\mathrm{B}}$ center and the unoccupied $\mathrm{O}_{2}{ }^{2-} \sigma^{*}$ via good $\sigma$-overlap is, again, promoted in the trigonal arrangement of the trinuclear $\mathrm{Cu}$ cluster (Figure 10). Consequently, $\mathrm{O}_{2}{ }^{2-} \sigma^{*}$ character would be present in the lower energy half-occupied $\mathrm{T} 3_{\mathrm{B}} \mathrm{MO}$, which would energetically enhance the donor-acceptor interaction with the reduced $\mathrm{T} 2$ and $\mathrm{T} 3_{\mathrm{A}} \mathrm{MOs}$. This role of $\mathrm{T}_{\mathrm{B}}$ is of particular importance for the proton-unassisted process.

This indicates that the O-O bond cleavage in MCOs does not intrinsically require the assistance of the proton, thus, allowing the reaction to proceed efficiently at high as well as at low $\mathrm{pH}$. In cytochrome c oxidase ( $\mathrm{CcO}$ ), on the other hand, it has been proposed that protonation of the peroxide by the Tyr residue near the binuclear heme- $\mathrm{Cu}_{\mathrm{B}}$ active site is necessary prior to the $\mathrm{O}-\mathrm{O}$ bond cleavage to achieve a low energy barrier to produce the ferryl-oxo-level $\mathrm{P}_{\mathrm{M}}$ intermediate. ${ }^{66-68}$ The distinction between the heme- $\mathrm{Cu}_{\mathrm{B}}$ site of $\mathrm{CcO}$ and the trinuclear $\mathrm{Cu}$ cluster site in MCO lies in the fact that in the MCOs, there are three $\mathrm{Cu}$ centers present that are capable of serving as both the source of electrons (the reduced $\mathrm{Cu}^{\mathrm{I}}$ ) and as Lewis acids (the oxidized $\mathrm{Cu}^{\mathrm{II}}$ ) in place of a $\mathrm{H}^{+}$for the efficient four-electron reduction of $\mathrm{O}_{2}$. In the binuclear heme- $\mathrm{Cu}_{\mathrm{B}}$ site of $\mathrm{CcO}$, a counterpart of the oxidized $\mathrm{T}_{\mathrm{B}}$ center is not available, and thus, $\mathrm{O}-$ $\mathrm{O}$ bond cleavage would require a proton to assist lowering the $\mathrm{O}_{2}{ }^{2-} \sigma^{*}$ orbital for favorable donor-acceptor FMO interactions. 
In summary we have shown that $\mathrm{O}_{2}$ binds in a fundamentally different way in the trinuclear $\mathrm{Cu}$ cluster relative to the $\mathrm{T} 3$ sites in $\mathrm{Hc} / \mathrm{Tyr}$ in that it bridges the $\mathrm{T} 2$ and $\mathrm{T} 3 \mathrm{Cu}$ 's due to the presence of $\mathrm{D}_{94}$ near the $\mathrm{T} 2$ site. This likely stabilizes the peroxide bound structure against loss of $\mathrm{O}_{2}$. The trinuclear $\mathrm{Cu}$ cluster further promotes cleavage of the $\mathrm{O}-\mathrm{O}$ bond by having FMOs specifically oriented for overlap with $\sigma^{*}$ LUMO of peroxide and by stabilizing the product of peroxide reduction through bridging at the trinuclear site in NI.

\section{Supplementary Material}

Refer to Web version on PubMed Central for supplementary material.

\section{Acknowledgements}

We thank A. J. Augustine for helpful discussion regarding the kinetics of PI formation and decay. This research was supported by NIH Grants DK31450. J. Y. gratefully acknowledges a Franklin Veatch Memorial Fellowship.

\section{References}

1. Solomon EI, Chen P, Metz M, Lee SK, Palmer AE. Angew Chem Int Ed 2001;40:4570-4590.

2. Solomon EI, Sundaram UM, Machonkin TE. Chem Rev 1996;96:2563-2605. [PubMed: 11848837]

3. Cole JL, Tan GO, Yang EK, Hodgson KO, Solomon EI. J Am Chem Soc 1990;112:2243-2249.

4. Spira-Solomon DJ, Allendorf MD, Solomon EI. J Am Chem Soc 1986;108:5318-5328.

5. Messerschmidt A, Ladenstein R, Huber R, Bolognesi M, Avigliano L, Petruzzelli R, Rossi A, FinazziAgró A. J Mol Biol 1992;224:179-205. [PubMed: 1548698]

6. Ducros V, Brzozowski AM, Wilson KS, Brown SH, Østergaard P, Schneider P, Yaver DS, Pedersen AH, Davies GJ. Nat Struct Biol 1998;5:310-316. [PubMed: 9546223]

7. Zaitseva I, Zaitsev V, Card G, Moshkov K, Bax B, Ralph A, Lindley P. J Bio Inorg Chem 1996;1:1523.

8. Bertrand T, Jolivalt C, Briozzo P, Caminade E, Joly N, Madzak C, Mougin C. Biochemistry 2002;41:7325-7333. [PubMed: 12044164]

9. Piontek K, Antorini M, Choinowski T. J Biol Chem 2002;277:37663-37669. [PubMed: 12163489]

10. Hakulinen N, Kiiskinen LL, Kruus K, Saloheimo M, Paananen A, Koivula A, Rouvinen J. Nat Struct Biol 2002;9:601-605. [PubMed: 12118243]

11. Roberts SA, Weichsel A, Grass G, Thakali K, Hazzard JT, Tollin G, Rensing C, Montfort WR. Proc Natl Acad Sci USA 2002;99:2766-2771. [PubMed: 11867755]

12. Enguita FJ, Marcal D, Martins LO, Grenha R, Henriques AO, Lindley PF, Carrondo MA. J Biol Chem 2004;279:23472-23476. [PubMed: 14764581]

13. Smith AW, Camara-Artigas A, Wang MT, Allen JP, Francisco WA. Biochemistry 2006;45:43784387. [PubMed: 16584173]

14. Taylor AB, Stoj CS, Ziegler L, Kosman DJ, Hart PJ. Proc Natl Acad Sci USA 2005;102:15459_ 15464. [PubMed: 16230618]

15. Garavaglia S, Cambria MT, Miglio M, Ragusa S, Iacobazzi V, Palmieri F, D’Ambrosio C, Scaloni A, Rizzi M. J Mol Biol 2004;342:1519-1531. [PubMed: 15364578]

16. Messerschmidt A, Luecke H, Huber R. J Mol Biol 1993;230:997-1014. [PubMed: 8478945]

17. Bento I, Martins LO, Lopes GG, Carrondo MA, Lindley PF. Dalton Trans 2005;3507-3513

18. Lee SK, George SD, Antholine WE, Hedman B, Hodgson KO, Solomon EI. J Am Chem Soc 2002;124:6180-6193. [PubMed: 12022853]

19. Brändén R, Deinum J. Biochim Biophys Acta 1978;524:297-304. [PubMed: 27222]

20. Aasa R, Brändén R, Deinum J, Malmström BG, Reinhammar B, Vänngård T. FEBS Lett 1976;61:115119. [PubMed: 174942]

21. Manabe T, Manabe N, Hiromi K, Hatano H. FEBS Lett 1972;23:268-270. [PubMed: 4634444]

22. Machonkin TE, Solomon EI. J Am Chem Soc 2000;122:12547-12560.

23. Palmer AE, Lee SK, Solomon EI. J Am Chem Soc 2001;123:6591-6599. [PubMed: 11439045] 
24. Yoon J, Mirica LM, Stack TDP, Solomon EI. J Am Chem Soc 2004;126:12586-12595. [PubMed: 15453791]

25. Yoon J, Mirica LM, Stack TDP, Solomon EI. J Am Chem Soc 2005;127:13680-13693. [PubMed: 16190734]

26. Yoon J, Solomon EI. Inorg Chem 2005;44:8076-8086. [PubMed: 16241158]

27. Yoon J, Solomon EI. Coord Chem Rev 2007;251:379-400.

28. Yoon J, Liboiron BD, Sarangi R, Hodgson KO, Hedman B, Solomon EI. Proc Natl Acad Sci USA 2007;104:13609-13614. [PubMed: 17702865]

29. Rulíšek L, Solomon EI, Ryde U. Inorg Chem 2005;44:5612-5628. [PubMed: 16060610]

30. Morie-Bebel MM, Morris MC, Menzie JL, McMillin DR. J Am Chem Soc 1984;106:3677-3678.

31. Shin W, Sundaram UM, Cole JL, Zhang HH, Hedman B, Hodgson KO, Solomon EI. J Am Chem Soc 1996;118:3202-3215.

32. Hassett RF, Yuan DS, Kosman DJ. J Biol Chem 1998;273:23274-23282. [PubMed: 9722559]

33. Blackburn NJ, Ralle M, Hassett R, Kosman DJ. Biochemistry 2000;39:2316-2324. [PubMed: 10694398]

34. Palmer AE, Quintanar L, Severance S, Wang TP, Kosman DJ, Solomon EI. Biochemistry 2002;41:6438-6448. [PubMed: 12009907]

35. Quintanar L, Stoj C, Wang TP, Kosman DJ, Solomon EJ. Biochemistry 2005;44:6081-6091. [PubMed: 15835897]

36. Cole JL, Ballou DP, Solomon EI. J Am Chem Soc 1991;113:8544-8546.

37. Augustine AJ, Quintanar L, Stoj CS, Kosman DJ, Solomon EI. Submitted

38. Magnus KA, Hazes B, Tonthat H, Bonaventura C, Bonaventura J, Hol WGJ. Proteins 1994;19:302309. [PubMed: 7984626]

39. Matoba Y, Kumagai T, Yamamoto A, Yoshitsu H, Sugiyama M. J Biol Chem 2006;281:8981-8990. [PubMed: 16436386]

40. Cuff ME, Miller KI, van Holde KE, Hendrickson WA. J Mol Biol 1998;278:855-870. [PubMed: 9614947]

41. Sundaram UM, Zhang HH, Hedman B, Hodgson KO, Solomon EI. J Am Chem Soc 1997;119:1252512540.

42. Frisch, MJ., et al. Gaussian 03, Revision C01. Gaussian, Inc; Pittsburgh, PA: 2004.

43. Noodleman L. J Chem Phys 1981;74:5737-5743.

44. Becke AD. J Chem Phys 1993;98:5648-5652.

45. Tenderholt, A. PyMOlyze. Stanford University; Stanford, CA, Ver. 1.5: 2006.

46. Chalupský J, Neese F, Solomon EI, Ryde U, Rulíšek L. Inorg Chem 2006;45:11051-11059. [PubMed: 17173465]

47. An additional geometry optimization on the $\mu_{3}-1,1,2-\mathrm{O}_{2}{ }^{2-}$ bridged PI structure was performed with a larger basis set, with triple- $\zeta 6-311 \mathrm{G}^{*}$ on $\mathrm{Cu}$ and coordinated $\mathrm{N} / \mathrm{O}$ atoms and $6-31 \mathrm{G}^{*}$ on the rest, to verify that the structures obtained in this study with the double- $\zeta$ quality basis set, with $6-31 \mathrm{G}^{*}$ on $\mathrm{Cu}$ and coordinated N/O atoms and $3-21 \mathrm{G}^{*}$ on the rest, are sound. As a result, it is found that the overall structure of PI remains the same and the geometric parameters are very similar to those obtained with the double- $\zeta$ basis set, as indicated in Table 1.

48. Mirica LM, Ottenwaelder X, Stack TDP. Chem Rev 2004;104:1013-1045. [PubMed: 14871148]

49. These energies are based on calculations using B3LYP functional with 6-31G* basis set on $\mathrm{Cu}$ and coordinated N/O atoms and 3-21G* basis set on the rest.

50. Eickman NC, Himmelwright RS, Solomon EI. Proc Natl Acad Sci USA 1979;76:2094-2098. [PubMed: 287049]

51. Quintanar L, Yoon J, Aznar CP, Palmer AE, Andersson KK, Britt RD, Solomon EI. J Am Chem Soc 2005;127:13832-13845. [PubMed: 16201804]

52. Lubien CD, Winkler ME, Thamann TJ, Scott RA, Co MS, Hodgson KO, Solomon EI. J Am Chem Soc 1981;103:7014-7016.

53. Penner-Hahn JE, Hedman B, Hodgson KO, Spira DJ, Solomon EI. Biochem Biophys Res Comm 1984;119:567-574. [PubMed: 6231927] 
54. Spira-Solomon DJ, Solomon EI. J Am Chem Soc 1987;109:6421-6432.

55. Note that the $\mathrm{Cu}$-peroxide interactions found in PI are different from those of the $\mu-\eta^{2}: \eta^{2}-\mathrm{O}_{2}{ }^{2-}$ sideon bridged structure where each of the $\mathrm{Cu} \mathrm{d}_{\mathrm{x}}{ }^{2}-\mathrm{y}^{2}$ orbitals form two strong $\sigma$-bonds with the $\mathrm{O}_{2}{ }^{2-}$ $\pi_{\sigma}{ }^{*}$ orbital. As a result, the exchange coupling is larger in the side-on structure $(J \sim-3700$ $\mathrm{cm}^{-1}, 49$ vide supra) compared to that of PI $\left(J \sim-670 \mathrm{~cm}^{-1}\right)$.

56. Resonance Raman experiments were performed on PI obtained from both T1Hg laccase and T1D Fet3p. However, we were not able to observe any vibrational signals above noise as these were dominated by the intense fluorescence of the aromatic residues when PI was irradiated in the near UV. Note that in oxy-hemocyanin, the intense absorption $\left(\sigma \sim 20000 \mathrm{M}^{-1} \mathrm{~cm}^{-1}\right)$ quenches the fluorescence in this region allowing the resonance Raman spectrum to be obtained.

57. Unpublished result.

58. To compare the energy difference between the direct proton transfer from a proton donor to a proton acceptor and the indirect proton transfer via a water molecule, we have modeled the proton transfer process between a formate ion and a formic acid at the B3LYP/6-31++ $\mathrm{G}^{* *}$ level. As a result, energy barriers for the proton transfer process directly between a formate and a formic acid and that mediated by a water molecule were estimated with relatively similar values of $\sim 7.9$ and $\sim 12.0 \mathrm{kcal} / \mathrm{mol}$, respectively. (The distance between $\mathrm{O}$ atoms accepting and donating the proton was fixed at $2.80 \AA$. See Figures S2, S3 and figure legends for details of the calculations.)

59. Note that three possible broken-symmetry states, with $|\beta \alpha \alpha\rangle,|\alpha \beta \alpha\rangle$, and $|\alpha \alpha \beta\rangle$ spin configurations, have very similar energies and contribute equivalently to the spin-frustrated ground state of NI. ${ }^{28}$ Thus, while the $\mid \beta \alpha \alpha>$ spin configuration contributes significantly in the early stage of O-O bond cleavage (which includes the transition state, vide infra), the other two spin configurations become equally important as all three $\mathrm{Cu}$ centers in the trinuclear cluster become oxidized.

60. As indicated in footnote 58, the energy barrier in the proton transfer process is estimated to be higher when it is mediated by a water molecule. However, the relative stability of PI+e+H, compared to PI $+\mathrm{e}$, can provide enough thermodynamic driving force to make the energy barrier in the proton transfer process still small relative to the overall transition state energy.

61. Hazes B, Magnus KA, Bonaventura C, Bonaventura J, Dauter Z, Kalk KH, Hol WGJ. Prot Sci 1993;2:597-619.

62. Sawyer, DT. Oxygen Chemistry. Oxford University Press; New York: 1991.

63. Aasa R, Brändén R, Deinum J, Malmström BG, Reinhammar B, Vänngård T. Biochem Biophys Res Comm 1976;70:1204-1209. [PubMed: 182162]

64. Andréasson LE, Brändén R, Reinhammar B. Biochim Biophys Acta 1976;438:370-379. [PubMed: 182231]

65. Huang HW, Zoppellaro G, Sakurai T. J Biol Chem 1999;274:32718-32724. [PubMed: 10551829]

66. Blomberg MRA, Siegbahn PEM. Biochim Biophys Acta 2006;1757:969-980. [PubMed: 16483535]

67. Blomberg MRA, Siegbahn PEM. J Compt Chem 2006;27:1373-1384. [PubMed: 16788913]

68. Blomberg MRA, Siegbahn PEM, Wikstrom M. Inorg Chem 2003;42:5231-5243. [PubMed: 12924894] 


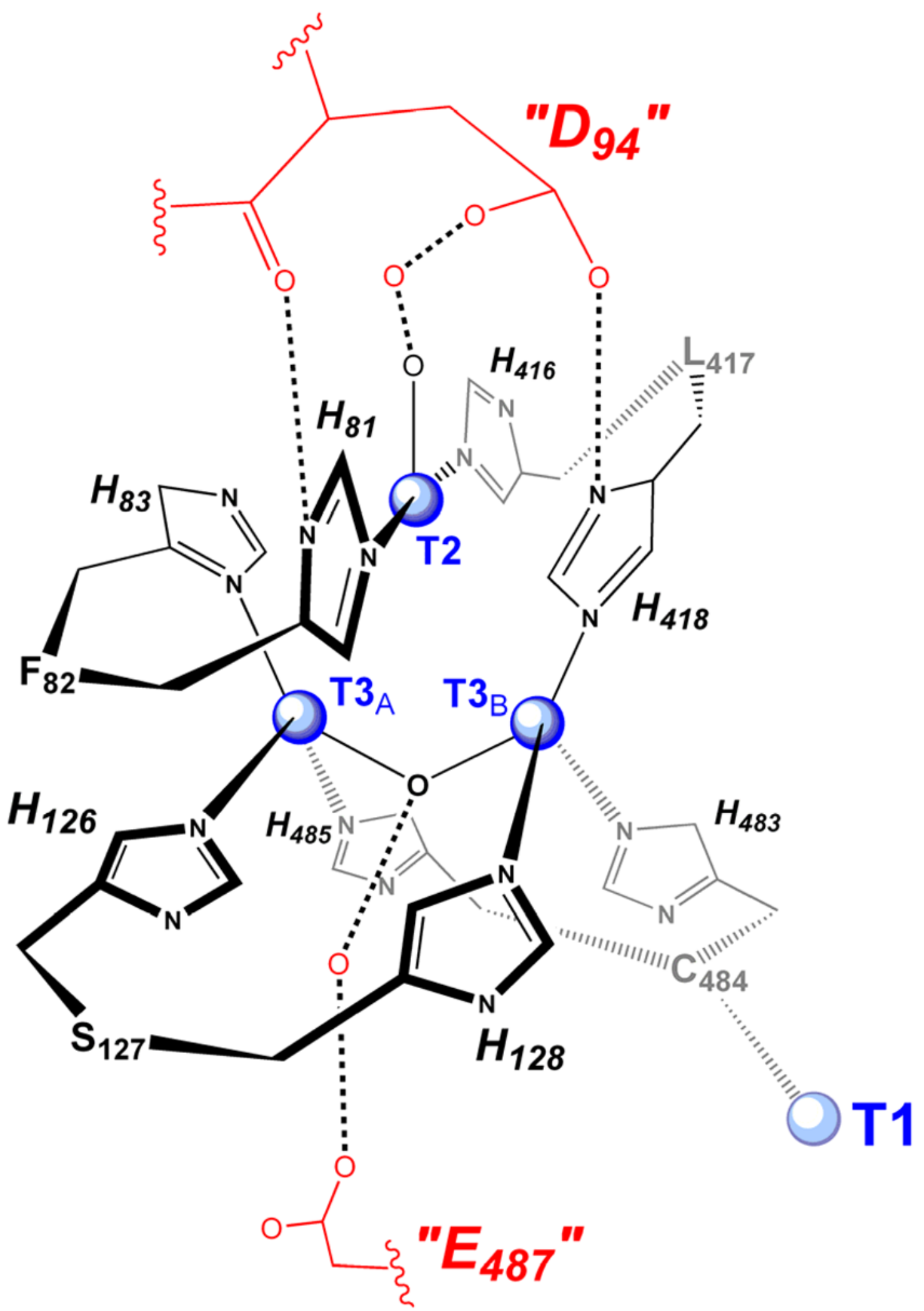

Figure 1.

A general description of the trinuclear $\mathrm{Cu}$ cluster in multicopper oxidases. For the purpose of correlating to the earlier mutation studies on Fet $3 p$, the residue numbers of Fet $3 p$ are given. Note that two nearby carboxylate residues in the second coordination sphere, $\mathrm{D}_{94}$ and $\mathrm{E}_{487}$, are also indicated (in red). Mutant studies indicate that these residues have critical roles in the $\mathrm{O}_{2}$ reactivity of the trinuclear $\mathrm{Cu}$ cluster. 


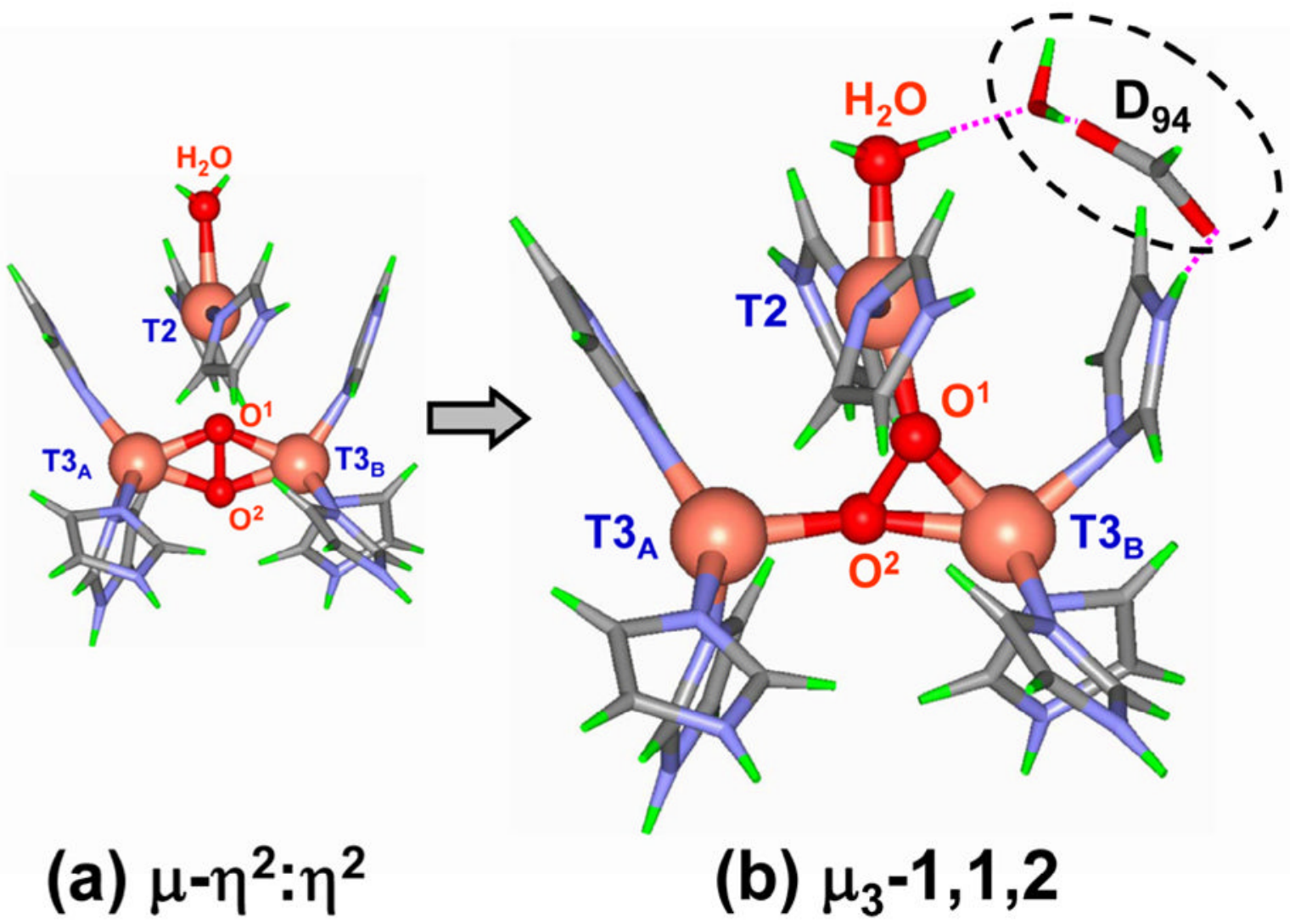

Figure 2.

Calculated structures of PI, (a) without $\mathrm{D}_{94}$, resulting in a side-on $\mu-\eta^{2}: \eta^{2}$ bridged geometry, and (b) with $\mathrm{D}_{94}$, resulting in a $\mu_{3}-1,1,2$ bridged geometry. Refer to Table 1 for geometric parameters. 


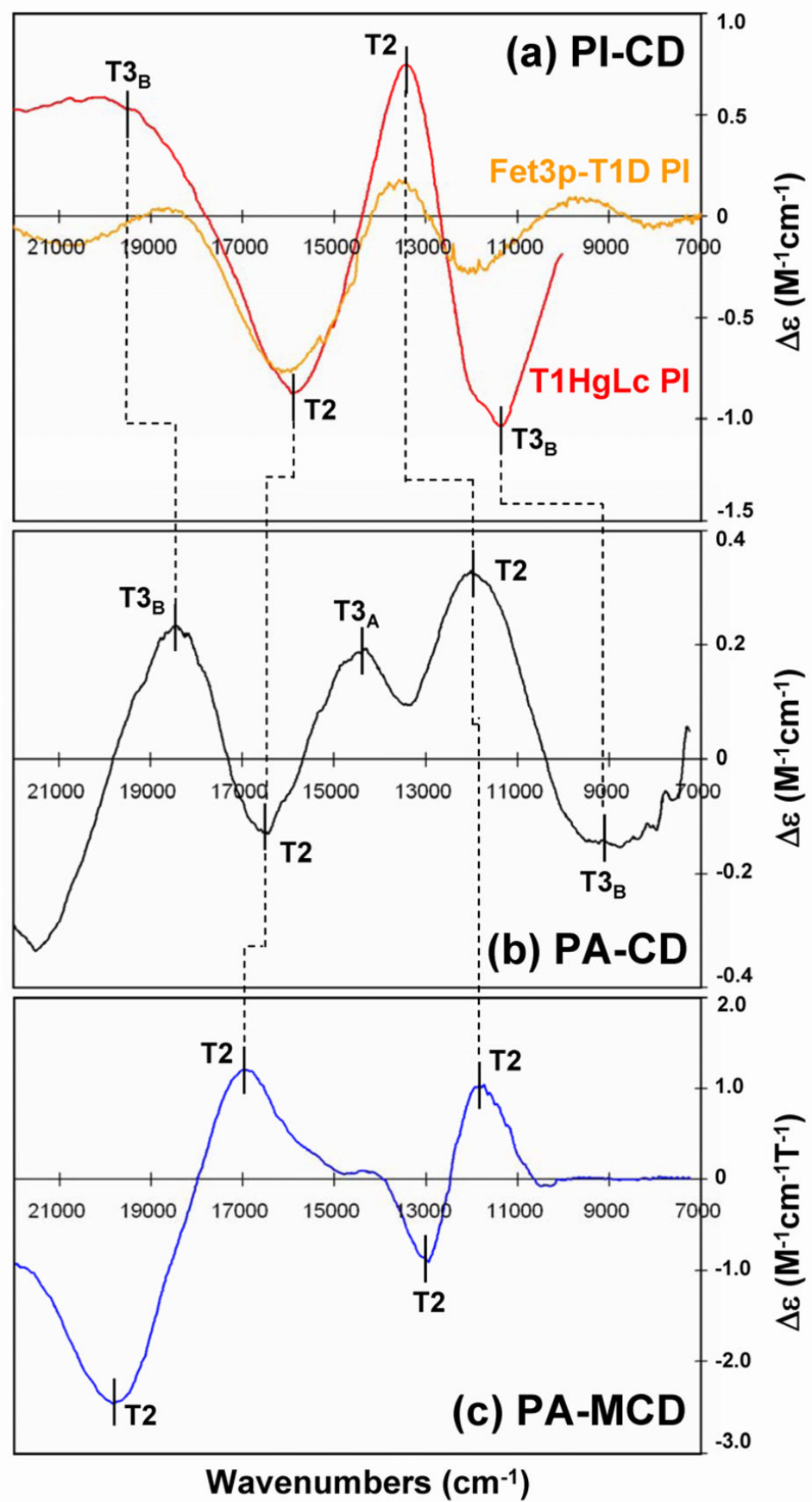

Figure 3.

Comparison and assignments of the LF transitions in PI and PA of T1HgLc in the CD and MCD spectra, adapted from earlier studies (refs. 31 and ${ }^{41}$ ): (a) $298 \mathrm{~K} \mathrm{CD} \mathrm{spectrum} \mathrm{of} \mathrm{PI,}$ where PI of T1HgLc is given in red $(100 \mathrm{mM}$ potassium phosphate buffer, $\mathrm{pH}=7.4) .298 \mathrm{~K}$ CD spectrum of PI from Fet3p-T1D is also given in orange $(100 \mathrm{mM}$ sodium phosphate buffer, $\mathrm{pH}=7.4$ ) to show CD features below $10000 \mathrm{~cm}^{-1}$ (adapted from ref. ${ }^{37}$ ); (b) $298 \mathrm{~K} \mathrm{CD}$ spectrum of PA (T1HgLc + 200-fold excess of $\mathrm{H}_{2} \mathrm{O}_{2}, 100 \mathrm{mM}$ potassium phosphate buffer, $\mathrm{pH}=6.0$ ); (c) $4.2 \mathrm{~K} \mathrm{MCD}$ spectrum of PA (T1 HgLc +200 -fold excess of $\mathrm{H}_{2} \mathrm{O}_{2}, 100 \mathrm{mM}$ potassium phosphate buffer, $\mathrm{pH}=6.0$ ). Indicated peak positions are based on simultaneous Gaussian fitting results using absorption, CD (for PI and PA), and MCD spectra (for PA). 
Spin Densities: $T 2=-0.61, T 3_{A}=0.06, T 3_{B}=0.52, O^{1}=0.00, O^{2}=0.13$ $J=-670 \mathrm{~cm}^{-1}$ (expt. $\left.J<-200 \mathrm{~cm}^{-1}\right)$

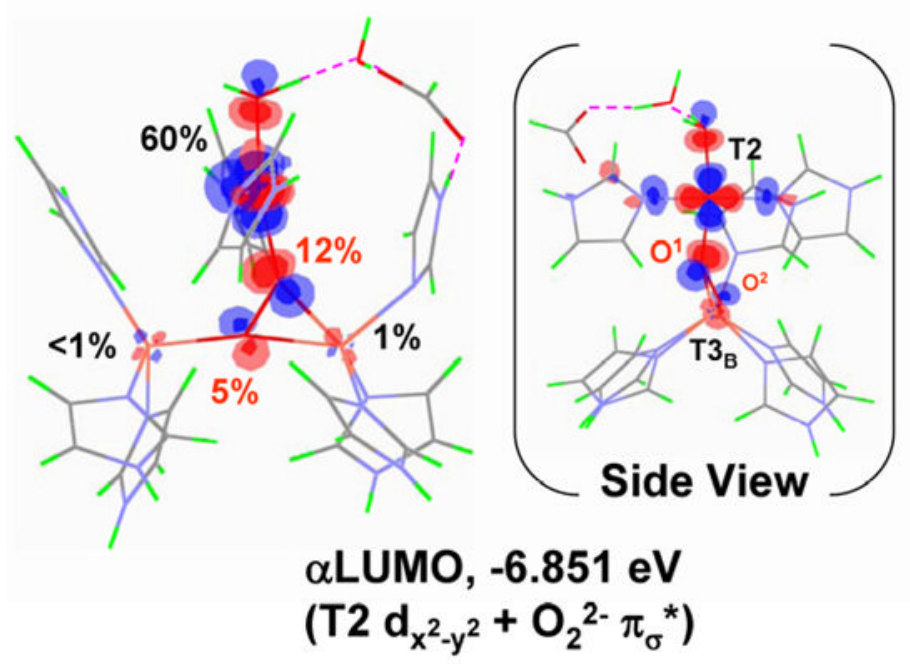

(a)

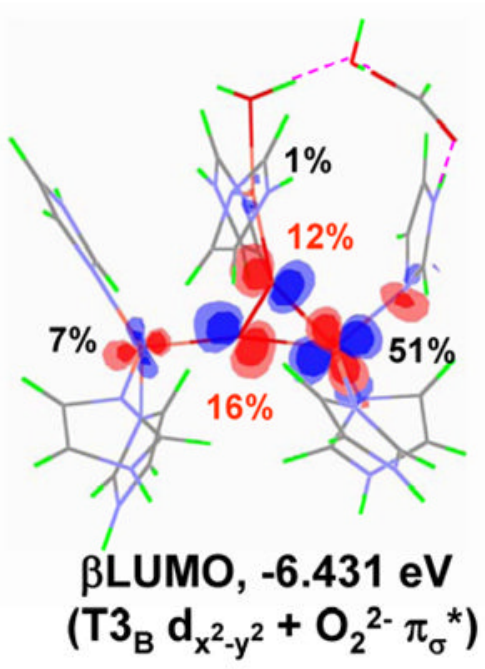

(b)

Figure 4.

Contours of the $\alpha$ - and $\beta$-LUMOs of PI+D 94 that are based on T2 $d_{x}{ }^{2}-y^{2}$ and T3 $3 d_{x}{ }^{2}-; y^{2}$, respectively, obtained from the broken-symmetry state $\left(\mathrm{M}_{\mathrm{S}}=0\right)$ calculation. Both LUMOs have significant peroxide $\pi_{\sigma}{ }^{*}$ characters. Overall spin densities, isotropic exchange constant $J$, and the $\%$ compositions are indicated, $\mathrm{Cu}$ centers in black and $\mathrm{O}$ atoms of peroxide in red. The side view of $\alpha$ LUMO is also shown in (a) for better view of the T2 $d_{x}^{2}-y^{2}$ orbital. 
Wavenumbers $\left(\mathrm{cm}^{-1}\right)$

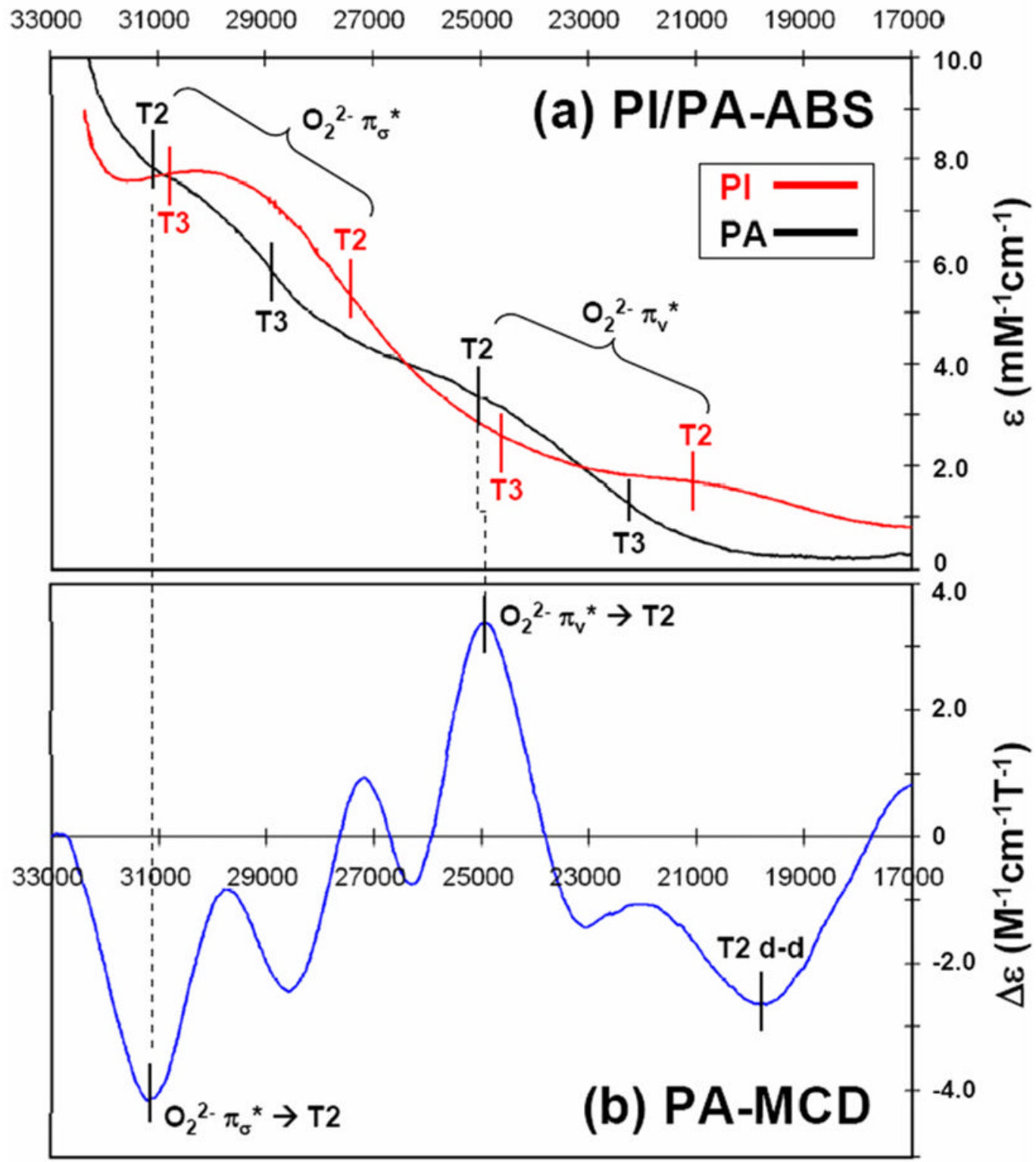

Figure 5.

Comparison and assignments of the CT transitions in PI and PA of T1 HgLc in the absorption and MCD spectra, adapted from earlier studies (refs. 31 and ${ }^{41}$ ): (a) $298 \mathrm{~K}$ absorption spectra of PI (red, $100 \mathrm{mM}$ potassium phosphate buffer, $\mathrm{pH}=7.4$ ) and PA (black, $\mathrm{T} 1 \mathrm{HgLc}+200$-fold excess of $\mathrm{H}_{2} \mathrm{O}_{2}, 100 \mathrm{mM}$ potassium phosphate buffer, $\mathrm{pH}=6.0$ ) and (b) $4.2 \mathrm{~K}$ MCD spectrum of PA (T1HgLc +200 -fold excess of $\mathrm{H}_{2} \mathrm{O}_{2}, 100 \mathrm{mM}$ potassium phosphate buffer, $\mathrm{pH}=6.0$ ). Indicated peak positions are based on simultaneous Gaussian fitting results using absorption, CD (for PI and PA), and MCD spectra (for PA). Note that bands not assigned in the MCD spectrum are associated with His $\rightarrow \mathrm{T} 2 \mathrm{CT}$ transitions. 


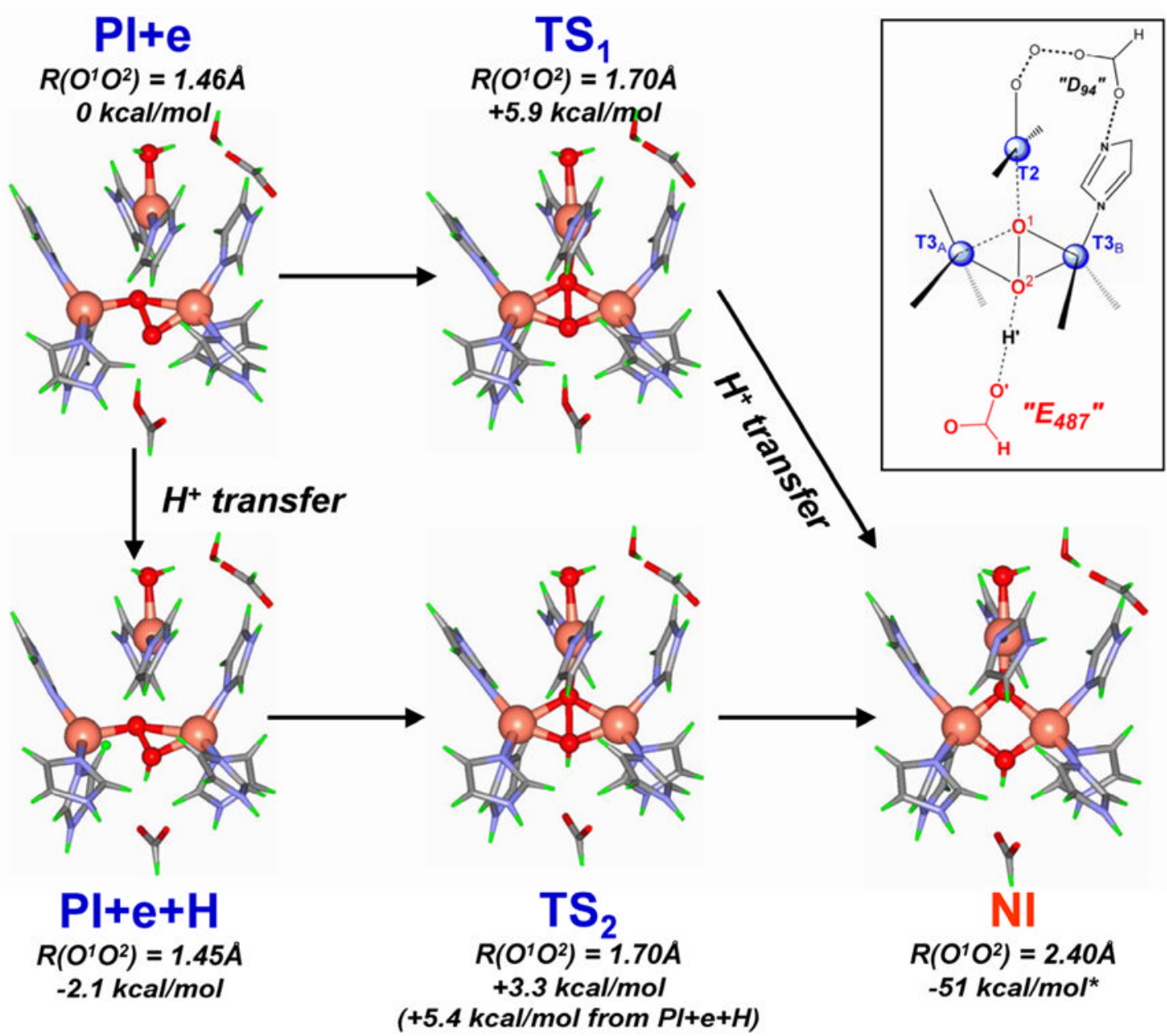

Figure 6.

Calculated structures of PI+e, PI+e+H, $\mathrm{TS}_{1}, \mathrm{TS}_{2}$, and NI, where the two transition states, $\mathrm{TS}_{1}$ and $\mathrm{TS}_{2}$, refer to transition states in the proton-unassisted and proton-assisted $\mathrm{O}-\mathrm{O}$ bond cleavage, respectively. In the inset, designations of atoms are indicated. The energies are based on single-point calculations using B3LYP functional with 6-311G* for $\mathrm{Cu}$ and coordinated N/ $\mathrm{O}$ atoms and $6-31 \mathrm{G}^{*}$ for the rest, with additional consideration of solvation effects using polarized continuum model (PCM/UAKS) with dielectric constant $(\sigma)$ of 4.0. The geometry optimizations were performed using B3LYP functional with 6-31 $\mathrm{G}^{*}$ for $\mathrm{Cu}$ and coordinated $\mathrm{N} / \mathrm{O}$ atoms and $3-21 \mathrm{G}^{*}$ for the rest. 


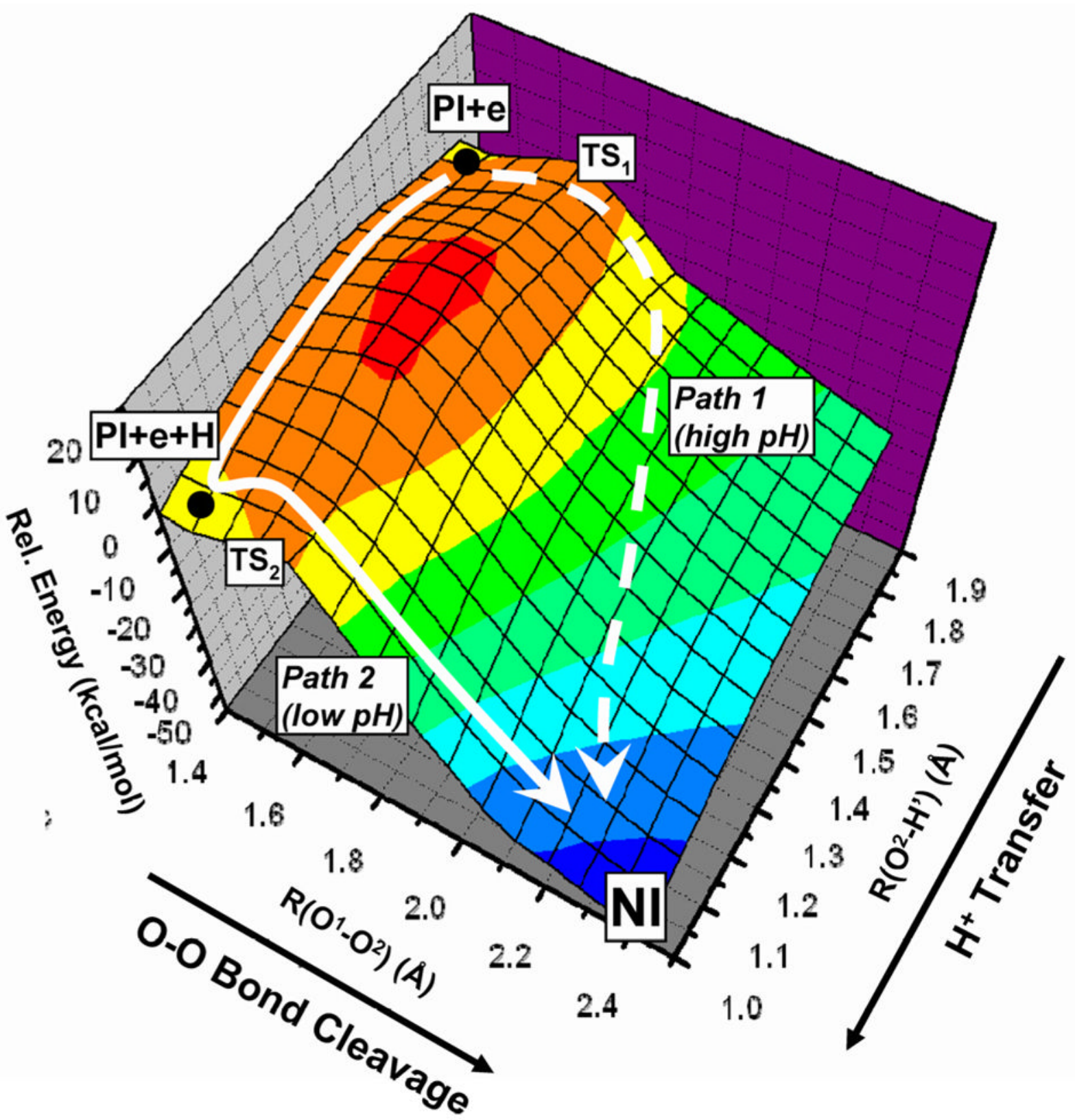

Figure 7.

Two-dimensional potential energy surface (2D-PES) of the O-O bond cleavage in the multicopper oxidases. Refer to Figure 6, inset, for designation of $\mathrm{O}^{1}, \mathrm{O}^{2}$, and $\mathrm{H}^{\prime}$. The energies are based on calculations using B3LYP functional with $6-31 \mathrm{G}^{*}$ for $\mathrm{Cu}$ and coordinated N/O atoms and $3-21 \mathrm{G}^{*}$ for the rest. 


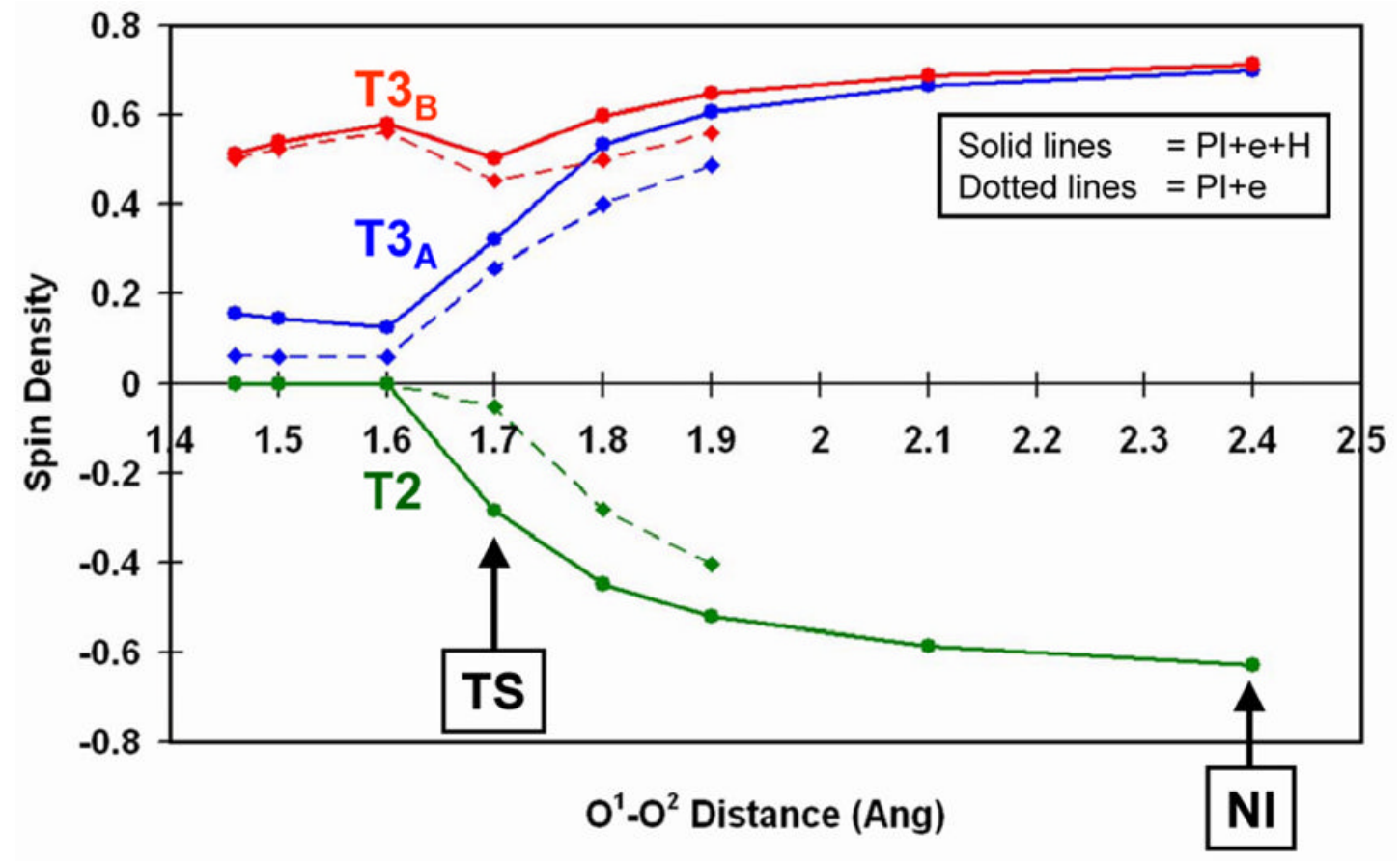

Figure 8.

Changes in spin densities upon O-O bond elongation. Solid lines indicate changes from PI+e $+\mathrm{H}$ to NI (i.e. with protonated peroxide) and dotted lines indicate changes from PI+e. PI+e with $\mathrm{R}\left(\mathrm{O}^{1}-\mathrm{O}^{2}\right)>1.9 \AA$ are not shown, as the proton transfer occurs spontaneously with no barrier at these $\mathrm{O}^{1}-\mathrm{O}^{2}$ distances. 
$\mathrm{Pl}+\mathrm{e}+\mathrm{H}$

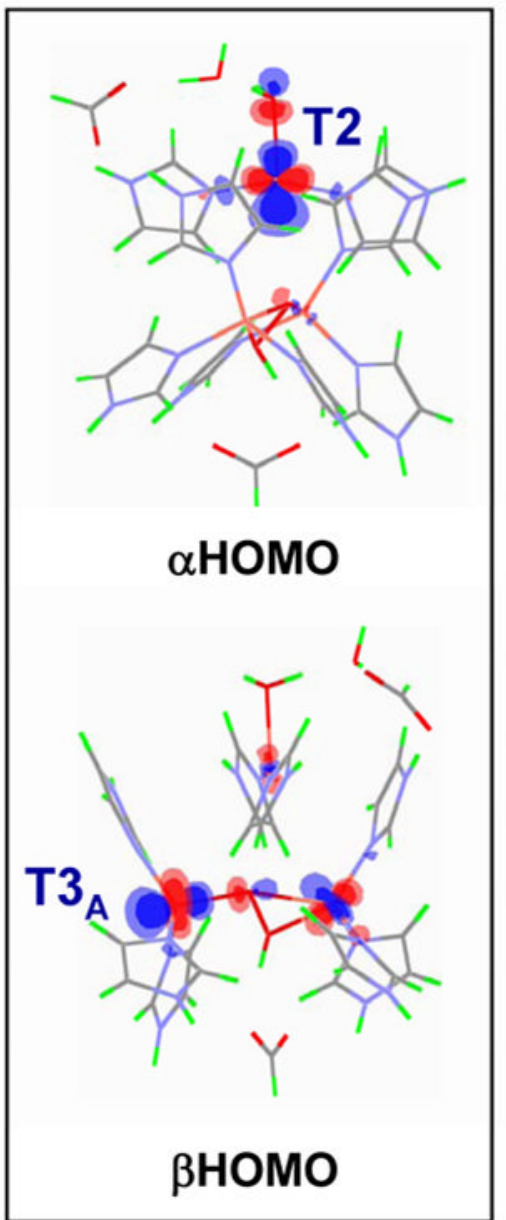

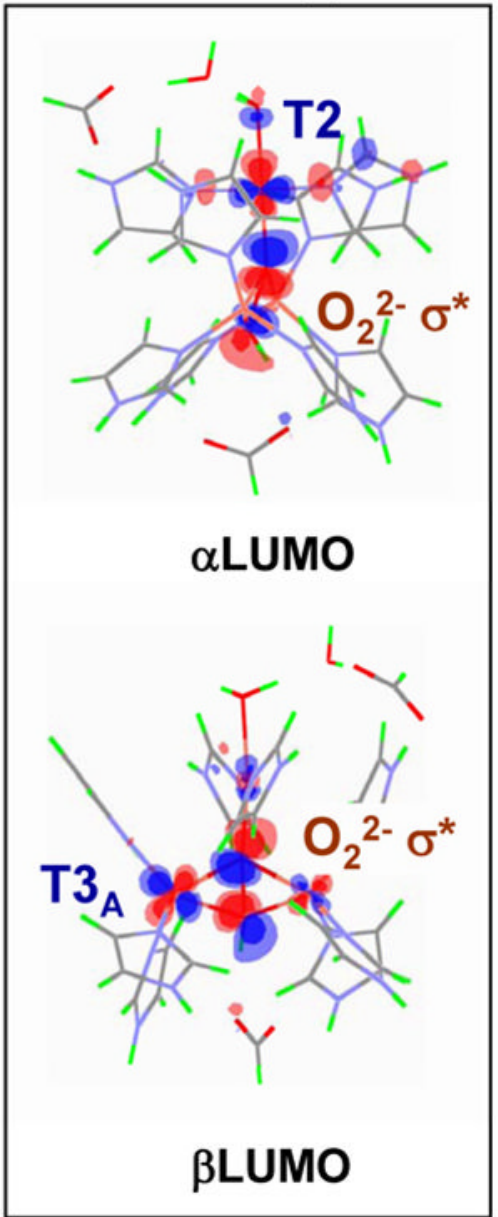

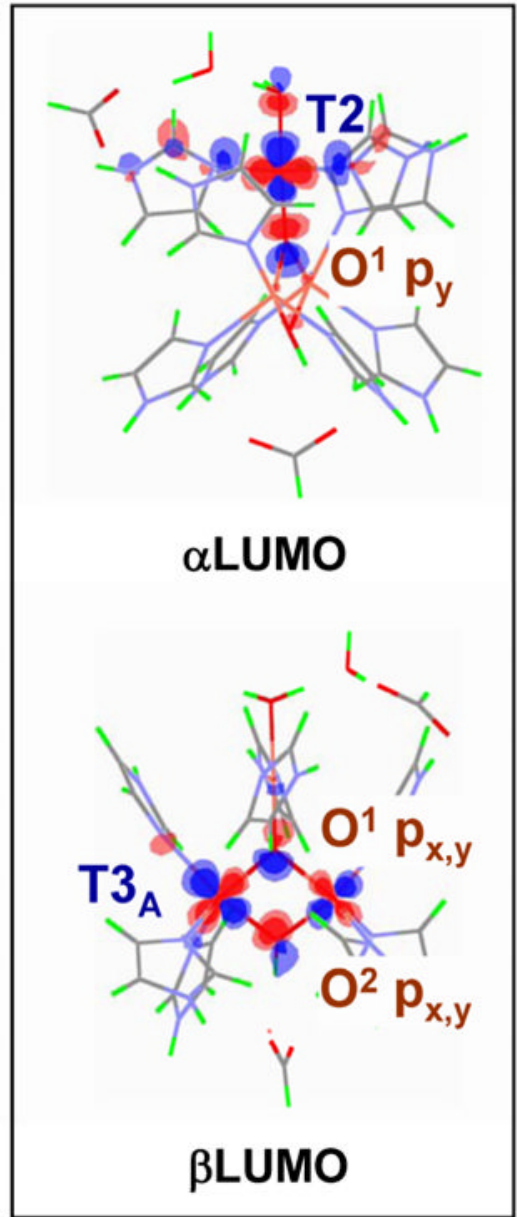

Figure 9.

Correlation of MOs involved in electron transfer during the $\mathrm{PI}+\mathrm{e}+\mathrm{H} \rightarrow \mathrm{TS}_{2} \rightarrow \mathrm{NI}$ process. In PI $+\mathrm{e}+\mathrm{H}$, only the $\mathrm{T} 3_{\mathrm{B}}$ center is oxidized, and the $\alpha$ - and $\beta$-HOMOs are derived from the highest energy d-electrons of $\mathrm{T} 2$ and $\mathrm{T} 3_{\mathrm{A}} \mathrm{Cu}$ centers. In $\mathrm{TS}_{2}$, both the $\mathrm{T} 2 \mathrm{~d}_{\mathrm{x}}{ }^{2}-\mathrm{y}^{2}$ based $\alpha \mathrm{HOMO}$ and T3 $3_{A} d_{x}{ }^{2}-y^{2}$ based $\beta$ HOMO form good overlap and mixing with the peroxide LUMO $\left(\mathrm{O}_{2}{ }^{2-}\right.$ $\left.\sigma^{*}\right)$ that promotes facile simultaneous two-electron transfer from the donor $\mathrm{T} 2$ and $\mathrm{T} 3_{\mathrm{A}} \mathrm{Cu}$ 's to the acceptor peroxide for the $\mathrm{O}-\mathrm{O}$ bond cleavage. In the final NI stage, the $\mathrm{T} 2$ and $\mathrm{T} 3_{\mathrm{A}} \mathrm{Cu}$ centers are fully oxidized and both $\mathrm{O}$ atoms fully reduced to $\mu_{3}$-oxo $(\mathrm{O} 1)$ and $\mu-\mathrm{OH}\left(\mathrm{O}^{2}\right)$ bridging ligands. The same type of MO correlation can be made for the $\mathrm{PI}+\mathrm{e} \rightarrow \mathrm{TS}_{1} \rightarrow \mathrm{NI}$ process. 


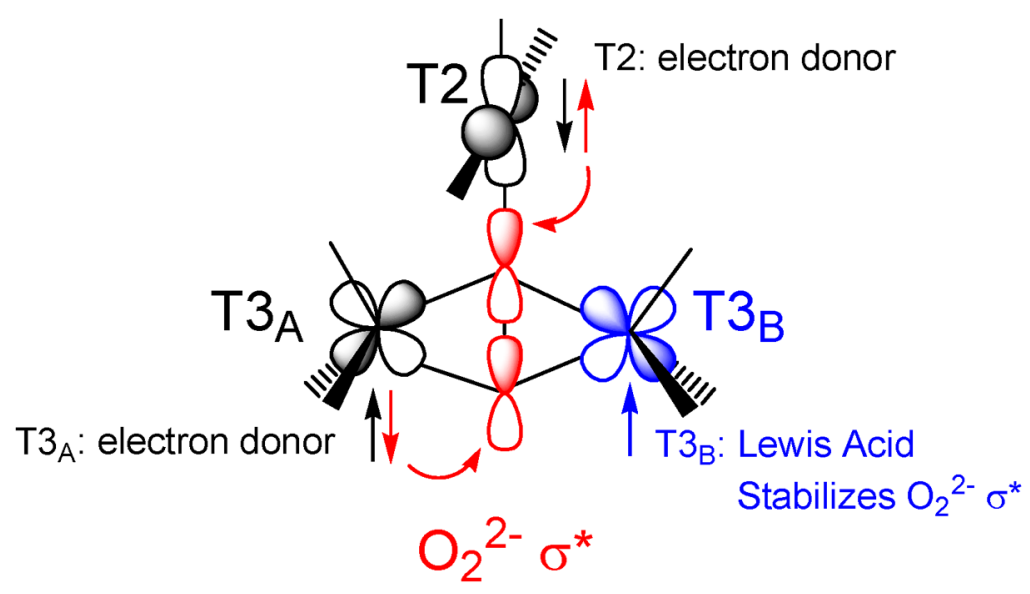

Figure 10.

Orbital interactions in the $\mathrm{O}-\mathrm{O}$ bond cleavage process. 
Table 1

Geometric Parameters for PI with and without $\mathrm{D}_{94}$ (Distances in $\AA$ and angles in $\left.{ }^{\circ}\right) .^{a}$

\begin{tabular}{|c|c|c|c|}
\hline & Without $D_{94}\left[\mu-\eta^{2}: \eta^{2}\right]$ & & \\
\hline $\mathrm{O}^{1}-\mathrm{O}^{2}$ & 1.475 & 1.457 & (1.435) \\
\hline $\mathrm{T} 2-\mathrm{T} 3_{\mathrm{A}}$ & 3.801 & 4.007 & (4.063) \\
\hline $\mathrm{T} 2-\mathrm{T} 3_{\mathrm{B}}$ & 4.006 & 3.682 & (3.714) \\
\hline $\mathrm{T} 3_{\mathrm{A}}-\mathrm{T} 3_{\mathrm{B}}$ & 3.686 & 4.066 & (4.197) \\
\hline $\mathrm{T} 2-\mathrm{H}_{2} \mathrm{O}$ & 2.390 & 1.997 & $(2.070)$ \\
\hline $\mathrm{T} 2-\mathrm{O}^{1}$ & 2.659 & 1.937 & (1.973) \\
\hline $\mathrm{T} 3_{\mathrm{A}^{-}} \mathrm{O}^{1}$ & 2.012 & 3.098 & (3.173) \\
\hline $\mathrm{T} 3_{\mathrm{A}}-\mathrm{O}^{2}$ & 1.979 & 2.062 & (2.199) \\
\hline $\mathrm{T} 3_{\mathrm{B}}-\mathrm{O}^{1}$ & 2.032 & 1.937 & (1.943) \\
\hline $\mathrm{T}_{\mathrm{B}}-\mathrm{O}^{2}$ & 1.928 & 2.045 & (2.033) \\
\hline $\mathrm{T} 2-\mathrm{O}^{1}-\mathrm{T} 3_{\mathrm{B}}$ & -- & 143.8 & (143.0) \\
\hline $\mathrm{T} 3_{\mathrm{A}}-\mathrm{O} 1-\mathrm{T} 3_{\mathrm{B}}$ & 131.4 & -- & -- \\
\hline $\mathrm{T} 3_{\mathrm{A}}-\mathrm{O} 2-\mathrm{T} 3_{\mathrm{B}}$ & 141.3 & 163.8 & (165.3) \\
\hline
\end{tabular}

${ }^{a}$ Geometric parameters presented are those obtained using B3LYP functional with 6-31G* basis set on Cu and coordinated N/O atoms and 3-21G* on the rest. In addition, those obtained using B3LYP functional with 6-311 $\mathrm{G}^{*}$ basis set on $\mathrm{Cu}$ and coordinated N/O atoms and 6-31G* on the rest are indicated in parentheses for the $\mu 3-1,1,2$-bridged structure. 